\title{
Mechanical Response of Thermoelectric Materials
}

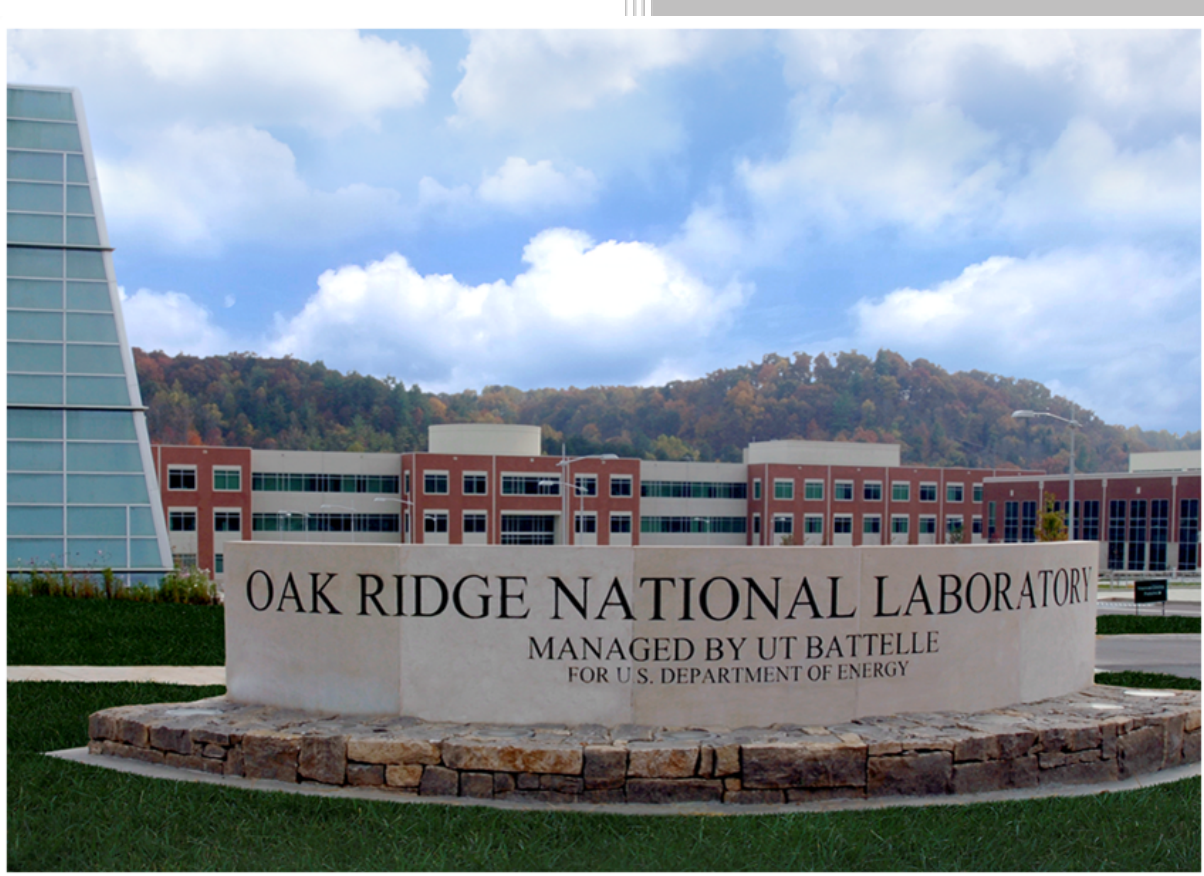

Approved for public release; distribution is unlimited.
A. A. Wereszczak
E. D. Case

May 2015 


\section{DOCUMENT AVAILABILITY}

Reports produced after January 1, 1996, are generally available free via US Department of Energy (DOE) SciTech Connect.

Website http://www.osti.gov/scitech/

Reports produced before January 1, 1996, may be purchased by members of the public from the following source:

National Technical Information Service
5285 Port Royal Road
Springfield, VA 22161
Telephone 703-605-6000 (1-800-553-6847)
TDD 703-487-4639
Fax 703-605-6900
E-mail info@ntis.gov
Website http://www.ntis.gov/help/ordermethods.aspx

Reports are available to DOE employees, DOE contractors, Energy Technology Data Exchange representatives, and International Nuclear Information System representatives from the following source:

Office of Scientific and Technical Information

PO Box 62

Oak Ridge, TN 37831

Telephone 865-576-8401

Fax 865-576-5728

E-mail reports@osti.gov

Website http://www.osti.gov/contact.html

This report was prepared as an account of work sponsored by an agency of the United States Government. Neither the United States Government nor any agency thereof, nor any of their employees, makes any warranty, express or implied, or assumes any legal liability or responsibility for the accuracy, completeness, or usefulness of any information, apparatus, product, or process disclosed, or represents that its use would not infringe privately owned rights. Reference herein to any specific commercial product, process, or service by trade name, trademark, manufacturer, or otherwise, does not necessarily constitute or imply its endorsement, recommendation, or favoring by the United States Government or any agency thereof. The views and opinions of authors expressed herein do not necessarily state or reflect those of the United States Government or any agency thereof. 
Materials Science and Technology Division

\title{
MECHANICAL RESPONSE OF THERMOELECTRIC MATERIALS
}

\author{
Andrew. A. Wereszczak \\ Materials Science and Technology Division \\ Oak Ridge National Laboratory \\ Oak Ridge, TN 37831 \\ wereszczakaa@ornl.gov \\ Eldon. D. Case \\ Chemical Engineering and Materials Science (retired) \\ Michigan State University \\ Lansing, MI 48824
}

Date Published: May 2015

Prepared by

OAK RIDGE NATIONAL LABORATORY

Oak Ridge, TN 37831-6283

managed by

UT-BATTELLE, LLC

for the

US DEPARTMENT OF ENERGY

under contract DE-AC05-00OR22725 



\section{CONTENTS}

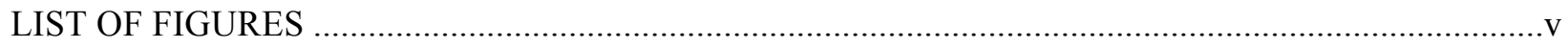

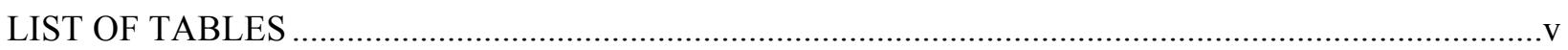

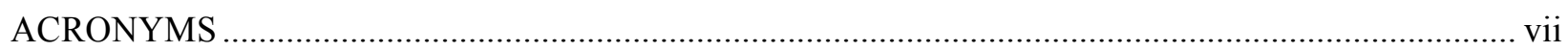

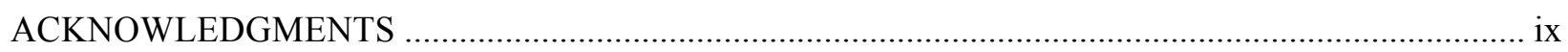

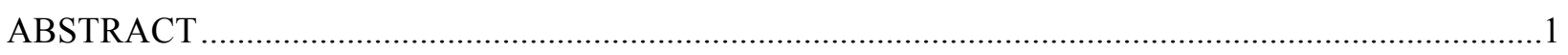

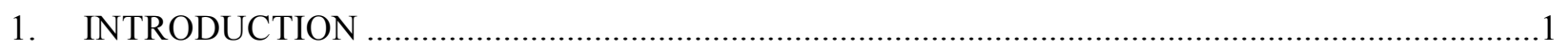

2. MECHANICAL CONSIDERATIONS OF TEMATS …................................................................

2.1 TENSILE STRESS LOCATION AND FLAW TYPES..................................................

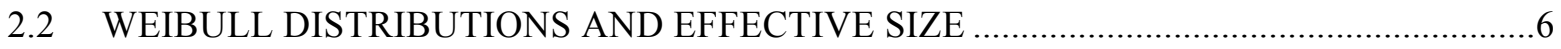

3. RELEVANT MECHANICAL PROPERTIES, CHARACTERISTICS, AND TEST

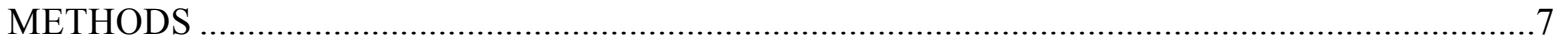

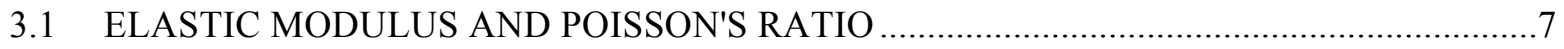

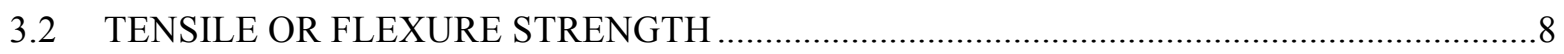

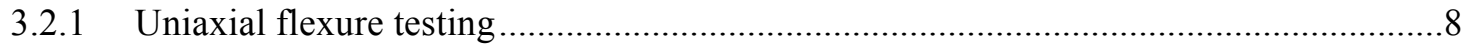

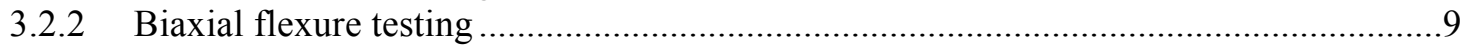

3.3 OTHER MECHANICAL CHARACTERISTICS ............................................................... 10

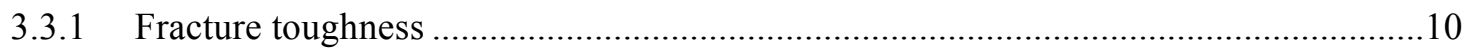

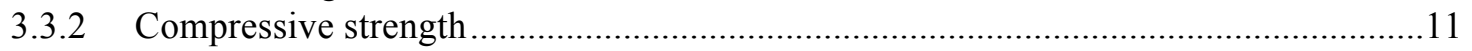

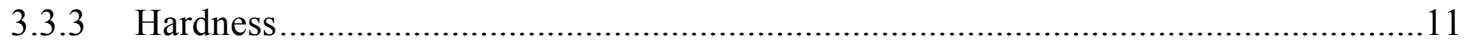

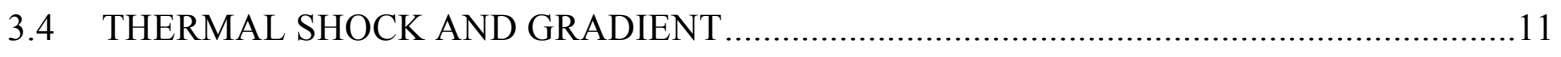

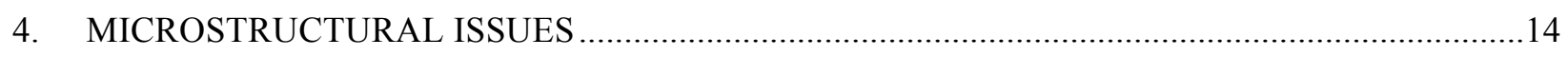

4.1 RELATIONSHIP OF PROCESSING AND MICROSTRUCTURE .....................................14

4.2 POROSITY IN THERMOELECTRIC MATERIALS ...........................................................15

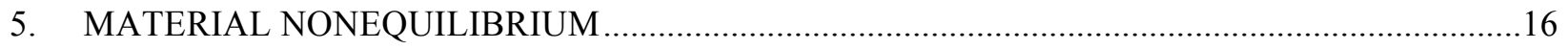

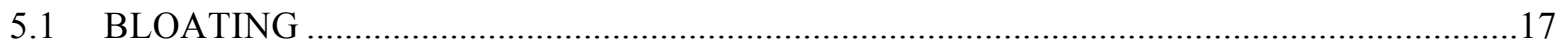

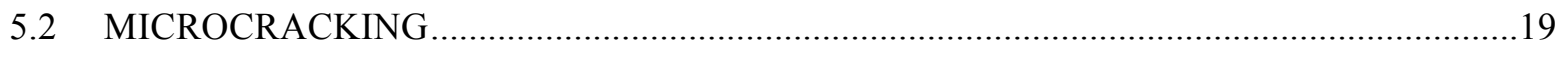

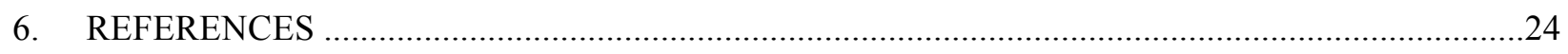

APPENDIX A. ELASTIC PROPERTIES OF VARIOUS THERMOELECTRIC

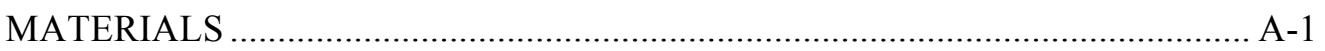

APPENDIX B. UNAXIAL FLEXURE STRENGTH OF VARIOUS

THERMOELECTRIC MATERIALS ..............................................................

APPENDIX C. BIAXIAL FLEXURE STRENGTH OF VARIOUS

THERMOELECTRIC MATERIALS .................................................................. 



\section{LIST OF FIGURES}

1. Schematic of a thermoelectric leg unit cell of a thermoelectric device that is subjected to a temperature gradient.

2. Directionality and the sign (i.e., tension vs. compression) of stress as a function of position within a thermoelectric leg subjected to an axial temperature gradient.....

3. Examples of one-dimensional (edge), two-dimensional (surface), and three-dimensional (volume) flaws that could be operative in thermoelectric legs

4. A flaw-type triangle may be used to illustrate the different potential strength-limiting flaw classifications for brittle materials

5. Examples of uniaxial and biaxial flexure test figures used with thermoelectric strength testing.....

6. Dilatometry can be an effective way to identify at what temperature a material may exhibit nonequilibrium and a change in mechanical response

7. For a $\mathrm{Co}_{0.95} \mathrm{Pd}_{0.05} \mathrm{Te}_{0.05} \mathrm{Sb}_{3}$ specimen hot pressed at $793 \mathrm{~K}$ at $74.4 \mathrm{MPa}$ maximum pressure, (a) a fracture surface of the specimen as a hot-pressed specimen and (b) a fracture surface of the same specimen, annealed at $973 \mathrm{~K}$ for $4 \mathrm{~h}$ in an argon atmosphere.

8. For a pulsed electric current $\mathrm{SnTe}$ specimen sintered at $673 \mathrm{~K}$ with a maximum pressure of $60 \mathrm{MPa}$, (a) a fracture surface of the as-densified specimen and (b) a fracture surface of the same specimen following annealing in argon at $873 \mathrm{~K}$

\section{LIST OF TABLES}

1. Example of effective size calculations for three-point bend testing for a skutterudite 



\section{ACRONYMS}

CARES ceramic analysis and reliability evaluation of structures

CTE

FEA

coefficient of thermal expansion

LAST

LASTT

PECS

RUS

SEM

TAGS

TE

TEA

TEMat

finite-element analysis

lead-antimony-silver-tellurium

lead-antimony-silver-tellurium-tin

pulsed electric current sintering

resonant ultrasound spectroscopy

scanning electron microscope

tellurium-antimony-germanium-silver

thermoelectric

thermal expansion anisotropy

thermoelectric material 



\section{ACKNOWLEDGMENTS}

The authors wish to thank the following for their contributions and support: J. Gibbs and J. Fairbanks [US Department of Energy (DOE)]; R. Johnson, D. Stinton, A. Haynes, H. Wang, M. Ferber, H. -T Lin, E. Fox, S. Waters, T. Kirkland, E. Lara-Curzio, R. Trejo, and W. Cai [Oak Ridge National Laboratory (ORNL)]; J. Sharp, R. McCarty, and A. Thompson (Marlow Industries); J. Salvador (General Motors); J. Yang (University of Washington); F. Ren (Temple University); J. Ni (Jet Propulsion Laboratory); R. Schmidt (Michigan State University); and O. Jadaan (University of Mount Union). The authors also thank ORNL's V. Ewing, M. Ferber, W. Koncinski, and R. Wiles for reviewing the manuscript and their helpful comments.

Support from the following sources is acknowledged: (1) the DOE Assistant Secretary for Energy Efficiency and Renewable Energy Office of Vehicle Technologies, as part of the Propulsion Materials Program, under contract DE-AC05-00OR22725 with UT-Battelle, LLC; (2) ORNL Work-for-Others sponsor General Motors; (3) Office of Naval Research (ONR) under Multidisplinary University Research Initiative Grant N000140310789; (4) ONR Defense University Research Instrumentation Program Grants N00014-09-1-0785 and N00014-07-1-073; (5) DOE Grant DE-FC26-04NT42281; (6) General Motors and DOE under contract DE-EEE000543, (7) Pacific Northwest National Laboratory under contract DEAC05-76RL01830; and (8) the DOE "Revolutionary Materials for Solid State Energy Conversion Center," an Energy Frontiers Research Center funded by the DOE Office of Science Office of Basic Energy Sciences under award DE-SC0001054. 



\begin{abstract}
A sufficient mechanical response of thermoelectric materials (TEMats) to structural loadings is a prerequisite to the exploitation of any candidate TEMat's thermoelectric efficiency. If a TEMat is mechanically damaged or cracks from service-induced stresses, then its thermal and electrical functions can be compromised or even cease. Semiconductor TEMats tend to be quite brittle and have a high coefficient of thermal expansion; therefore, they can be quite susceptible to mechanical failure when subjected to operational thermal gradients. Because of this, sufficient mechanical response (vis-a-vis, mechanical properties) of any candidate TEMat must be achieved and sustained in the context of the service-induced stress state to which it is subjected. This report provides an overview of the mechanical responses of state-of-the-art TEMats; discusses the relevant properties that are associated with those responses and their measurement; and describes important, nonequilibrium phenomena that further complicate their use in thermoelectric devices. For reference purposes, the report also includes several appendixes that list published data on elastic properties and strengths of a variety of TEMats.
\end{abstract}

\title{
1. INTRODUCTION
}

The sought electrical and thermal functions of a thermoelectric (TE) material (TEMat), or TE leg, can only occur if its microstructure is contiguous throughout. Cracking or other time- or service-dependent mechanisms (e.g., porosity increases associated with material swelling) that break or compromise that microstructural continuity will, or can, render the TEMat or TE leg permanently inoperable. Therefore, understanding and managing such mechanically based damage are critical to the successful exploitation of any candidate TEMat.

To start to understand a TEMat's potential susceptibility to cracking or fracture, one must be cognizant of the potential stress states a TE leg could be subjected to during its anticipated service. A TE leg or TE device inherently functions when it is subjected to an axial temperature gradient (in the case of a leg) or when the opposing ends of a TE device have unequal temperatures. A schematic of the TE leg unit cell (Fig. 1) is used to introduce a discussion of service stresses that can lead to a cracked TEMat and TE leg if the magnitude of the maximum (tensile) stress is sufficiently high.

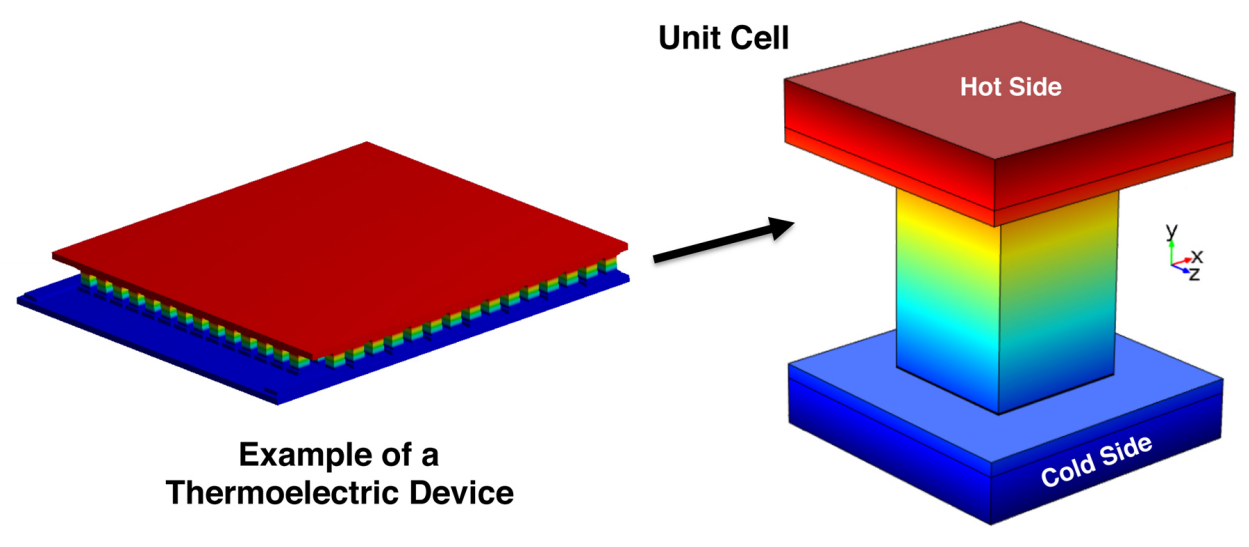

Fig. 1. Schematic of a thermoelectric leg unit cell of a thermoelectric device that is subjected to a temperature gradient. The center prismatic shape is the thermoelectric leg, and the larger sized ends represent the metal-clad substrates to which it is bonded. 
A TE device is an elegant electrical package comprising an array of TE legs connected in electrical series. The TE device is fabricated from many different materials:

- TEMats [lead-antimony-silver-tellurium (LAST), skutterudites, etc.] typically fabricated into a prismatic shape,

- structurally bearing substrates that have metal cladding (e.g., copper or aluminum) bonded directly to electrically insulative ceramics (e.g., $\mathrm{Al}_{2} \mathrm{O}_{3}, \mathrm{AlN}, \mathrm{BeO}$ ), and

- metallizations (e.g., brazes) that bond the TE legs to the metal-clad substrates.

Stresses are created in a TE leg within a TE device from two sources. The first is thermoelastic stresses that stem from coefficient of thermal expansion (CTE) mismatches from all the dissimilar and interconnected materials used in the TE device in combination with the existing thermal gradient of service. The second is from different combinations of the constituents having different processing temperatures and different consequential strain-free temperatures prior to the final fabrication of the TE device. For example, the metal-clad substrates are normally processed at very high temperatures (e.g., above $1,000^{\circ} \mathrm{C}$ for copper-clad- $\mathrm{Al}_{2} \mathrm{O}_{3}$ ). The metallization is actually often a multilayer system of dissimilar metals and metal platings, each deposited at different temperatures (typically each at several hundred degrees Celsius) from the material it is contact with. The final assembly of the TE device may occur at yet a different temperature. All of these different processing temperatures of the constituents and the fabrication of the final TE device, in combination with them all having dissimilar CTEs, create a nonintuitive residual stress state in the TE leg and TE device. This TE-device-specific stress state essentially requires that computational finite-element analysis (FEA), assuming all the thermoelastic properties of each constituent are confidently known, be performed to understand both the incipient residual stress state and the superimposing stress state that result from a service temperature gradient.

An example of the stress fields in a TE leg that could arise from an operational temperature gradient is shown in Fig. 2. The stress directions are in context to the Cartesian axes shown next to the TE leg in Fig. 1. The gradients shown and their directionality are functions of the different materials and parameters selected (TEMats, metallizations, processing temperatures, leg dimensions, etc.); therefore, this example should not be interpreted by the reader as representing the stress states for all TE legs and devices because that would be erroneous. Planar cross sections at three axial (i.e., Y-axis in Fig. 1) locations are shown in Fig. 2 for stresses in the X, Y, and Z directions. The three legends in Fig. 2 discriminate between regions of tension and compression for all nine images. The $\sigma_{X}$ and $\sigma_{Z}$ stress fields are identical, though rotated $90^{\circ}$ with respect to each other, because of the tetragonal isotropy of the TE leg prismatic shape relative to the direction of the temperature gradient.

Attention is drawn to the fact there are tensile stresses located at the edges, surface, and within the bulk of the TE leg, depending on axial position. This fact is seminal. Any cracking (and associated loss in TE function) that occurs in TEMats will be a direct consequence of the magnitude of any of those tensile stresses being sufficiently large. The tensile stresses that can cause cracking are a direct function of the value of the TEMat's elastic properties and its tensile failure strength.

This report is largely devoted to measurement and discussion of the mechanical properties of TEMats. It is knowledge of these values that enables the engineer or designer to fabricate TE devices out of a desired candidate TEMat and ultimately have that TE device successfully function so that exploitation of the TEMat's TE efficiency can occur. 


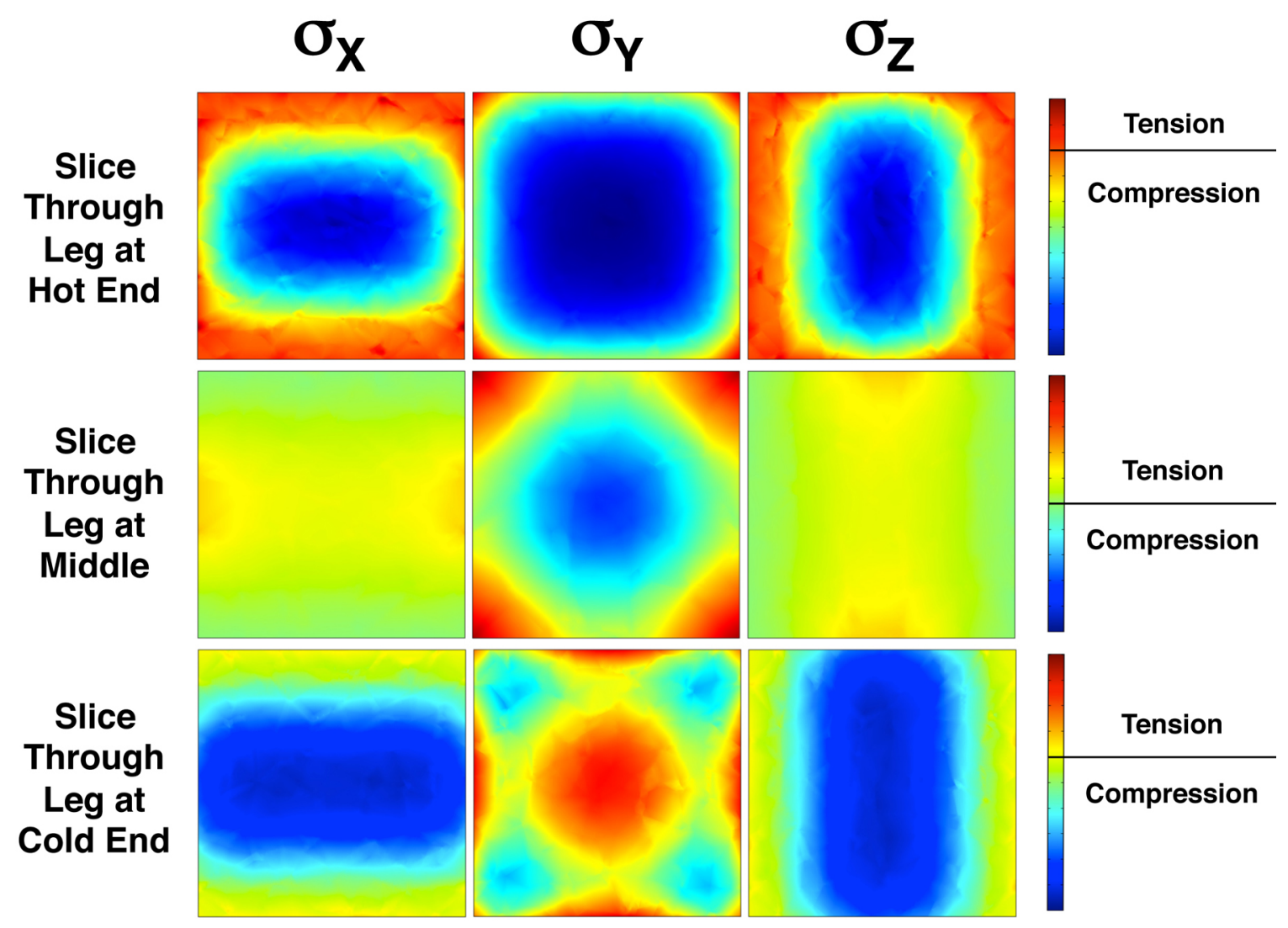

Fig. 2. Directionality and the sign (i.e., tension vs. compression) of stress as a function of position within a thermoelectric leg subjected to an axial temperature gradient. The stress field and their magnitudes are functions of many different parameters, and this illustration is for an arbitrary case that does not represent all cases. Each stress-color legend corresponds to the three horizontal images to its left.

\section{MECHANICAL CONSIDERATIONS OF TEMatS}

Thermoelectric materials have a low fracture toughness and are therefore brittle like other semiconductor materials, as well as ceramics and glasses. This fact introduces at least five separate issues that must be considered in the structural design of a TE leg and TE device that are different from, or that do not need attention when, designing with metallic components. The five primary issues are as follows.

- Tension-compression asymmetry. For the same amount of stressed material, brittle materials are weaker in tension than they are in compression. The tensile failure stress is often at least one order of magnitude lower than it is in compression for many brittle materials. For example with a TEMat, Ravi et al. [1] measured a compression-to-tension strength ratio of $\sim 10$. Therefore, the tensile response is of much greater concern than the compressive response when generating strength data for the design of brittle material components such as TE legs and TE devices.

- Use of maximum first principal stress. For design, tensile or maximum first principal stress is followed. A brittle material component is almost always subjected to a multiaxial or shear-based condition; however, it is the first principal stress field (or tensile component of shear in the case of shear loading) to which attention is given. There is ample literature and brittle material component design software devoted to this subject [2-4] indicating this approach has been used for the last few 
decades. A shear-based criterion (e.g., von Mises) of stress analysis, often used with metallic component design, should not be used for the design of brittle material components.

- Location of the tensile stress. The failure of brittle materials and brittle material components can initiate at an edge (if edges exist in the component obviously), at a surface, or from within the interior. The possibility of any of these occurring needs to be given serious consideration. Life prediction codes \{e.g., ceramic analysis and reliability evaluation of structures (CARES) [4]\} allow the user to take into account the possible strength limitation from edges, surfaces, or the interior or volume, normally in conjunction with fractography [5] and consequential strength-data censoring. This phenomenon is a contributing reason why the strength of a brittle material is a material characteristic and not a material property.

- Tensile failure stress is represented statistically not deterministically. The statistical distribution of tensile strength is allied with the size distribution of the flaw populations that limits them. The twoparameter Weibull distribution has been used historically to fit strength data [6].

- Tensile-strength-size-scaling. Brittle materials are known to exhibit a phenomenon in which a larger amount of stressed material will be weaker in tension than a smaller amount of the same material. This is often described using the "weakest-link-in-a-chain" analogy. This phenomenon is a contributing reason why the strength of a brittle material is a material characteristic and not a material property. Tensile-strength-size-scaling is described in detail in ASTM C1683 [7]. TEMats are expected to exhibit tensile-strength-size-scaling, so it is anticipated that a larger sized TE leg will crack at a lower tensile stress than a smaller sized TE leg of the same material.

While the first two issues are indeed relevant to TEMat and TE device development, the latter three deserve more discussion because their relevance has greater visibility and is of more importance to TEMat process engineers and TE device designers.

\subsection{TENSILE STRESS LOCATION AND FLAW TYPES}

Cracks in prismatically shaped TE legs can initiate at an edge, surface, or from within (i.e., volume). Their initiation is always linked to some flaw type whose size $(2 c)$ is related to a critical tensile stress $(S)$, flaw shape $(Y)$, and material fracture toughness $\left(K_{I c}\right)$ according to the classical Griffith equation [8],

$$
S=\frac{K_{I c}}{Y \sqrt{c}},
$$

and rearranging and solving for flaw size,

$$
\text { FlawSize }=2 c=2\left(\frac{K_{I c}}{Y \cdot S}\right)^{2}
$$

Examples of potential strength-limiting flaws on or in a TEMat are shown in Fig. 3, but there can be many different types of flaws that limit strength. A listing of some of those flaws is shown in Fig. 4. Fractography [5] of failed strength-test specimens is the only way to conclusively identify what the actual strength-limiting flaw is. 

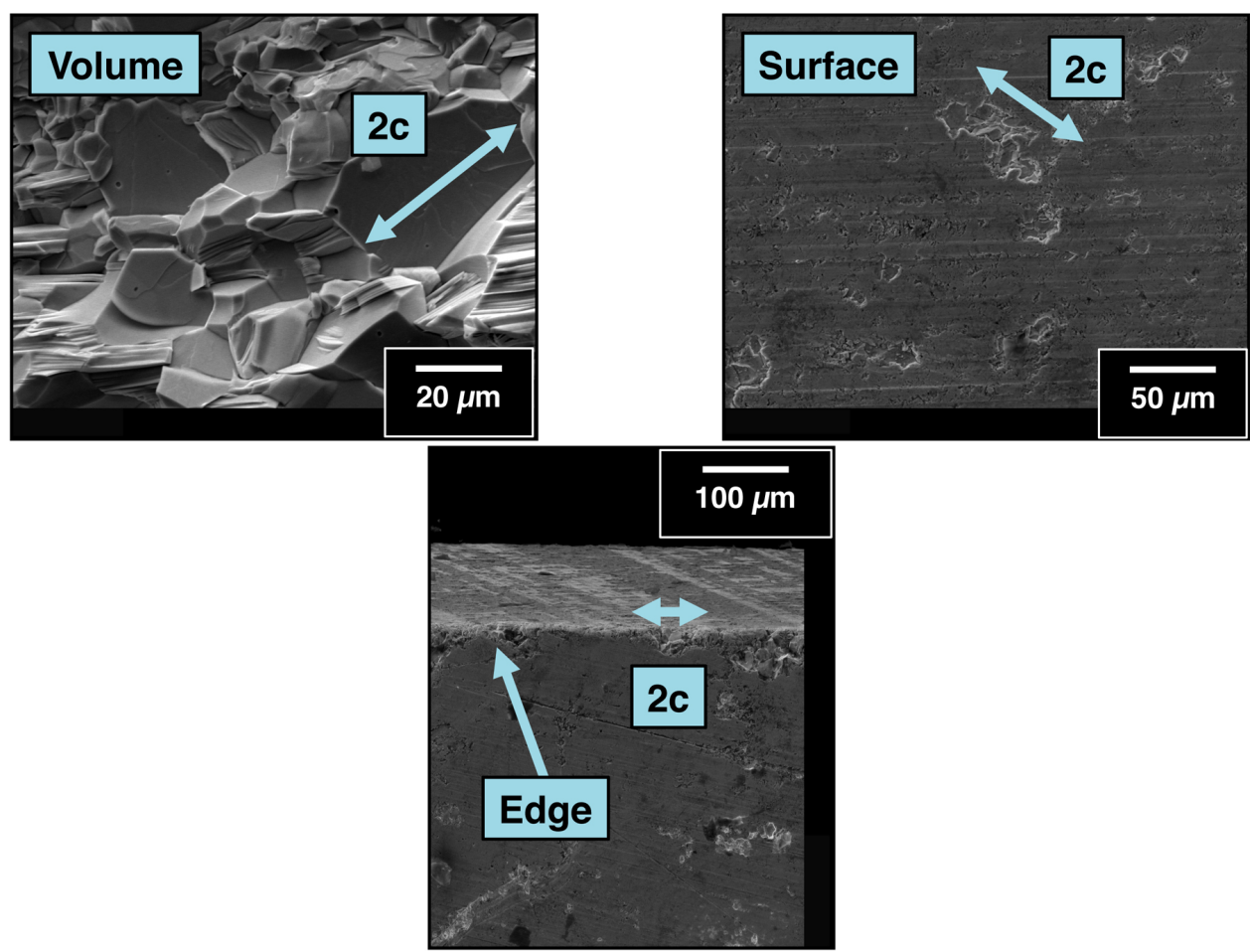

Fig. 3. Examples of one-dimensional (edge), two-dimensional (surface), and three-dimensional (volume) flaws that could be operative in thermoelectric legs.

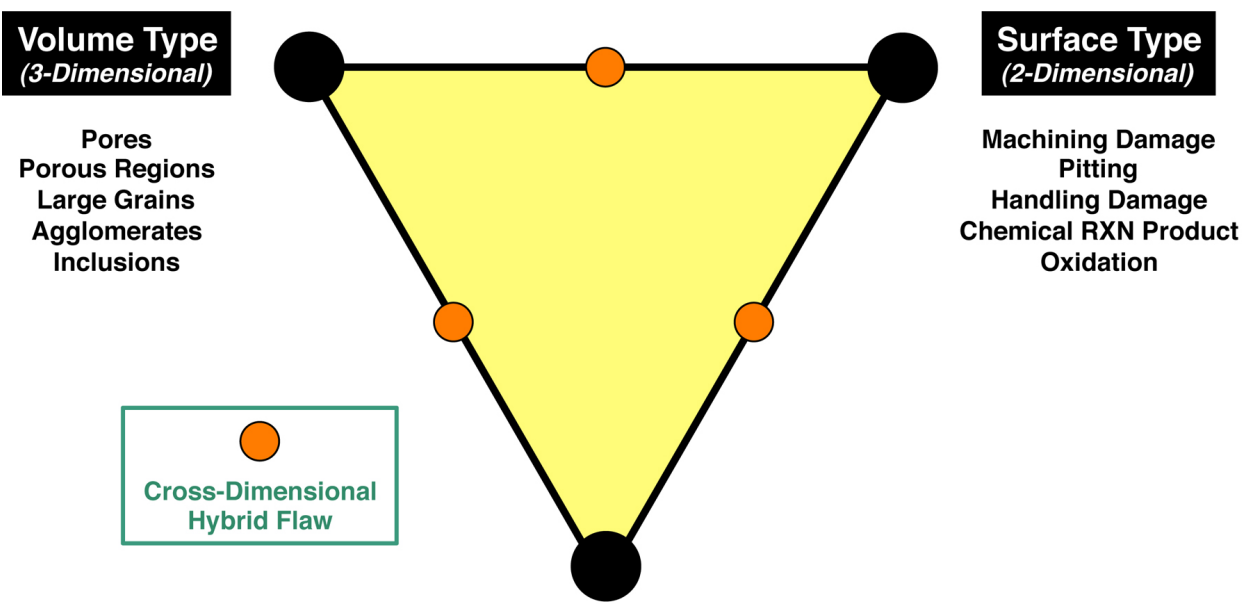

Edge Type (1-Dimensional)

Edge chipping

Fig. 4. A flaw-type triangle may be used to illustrate the different potential strength-limiting flaw classifications for brittle materials. Because TE legs have edges, all three of the above types can be operative.

Failure analysis is very important to both TEMat development and TEMat implementation in a TE device. It helps improve TEMat processing by identifying strength-limiting flaw types that can then potentially be removed with more attentive processing or be reduced in size [thus increasing $S$ in Eq. (1)]. While the entire flaw population is of interest, it is the largest flaws (i.e., those associated with the lowest tensile or 
flexure strengths) that deserve attention and mitigation. Failure analysis is also needed for censoring strength data for correct use in the structural design of the leg or device using the TEMat.

Machining practices and quality can affect which flaw types or locations shown in Fig. 4 are dominant, and this issue is relevant to TE leg fabrication. A tremendous amount of research and development occurred through US Department of Energy and Department of Defense sponsorship of engineered ceramic technology throughout the 1980s and 1990s. As the development of brittle material matures, and the strength-limiting size of volume-type flaws (e.g., pores, porous regions, agglomerates, large grains) decreases, strength limitation gets shifted to surface (and edge) locations of a brittle material specimen or component. Therefore, management of surface-type flaws (e.g., machining damage, handling damage, chipping) then becomes important to the overall strength integrity of that brittle material component. The importance of these types of flaws manifested itself in the creation of surface-grinding standardization for brittle materials [9].

\subsection{WEIBULL DISTRIBUTIONS AND EFFECTIVE SIZE}

The two-parameter Weibull distribution is traditionally used to represent the scatter in brittle material strength data [6]. Computer statistical software, such as WeibPar [10], evaluates the parameters for any given set of strength data. The tensile-strength-size-scaling character for edge-, surface- and volume-type flaw strength limitation is also accounted for in their functions according to [7]

$$
\begin{aligned}
& P_{f}=1-\exp \left[-k_{L} L\left(\frac{S_{\text {Tens }}}{\sigma_{0 L}}\right)^{m_{L}}\right], \text { or } \\
& P_{f}=1-\exp \left[-k_{A} A\left(\frac{S_{\text {Tens }}}{\sigma_{0 A}}\right)^{m_{A}}\right], \text { or } \\
& P_{f}=1-\exp \left[-k_{V} V\left(\frac{S_{\text {Tens }}}{\sigma_{0 V}}\right)^{m_{V}}\right],
\end{aligned}
$$

where $P_{f}$ are probabilities of failure; $k_{L} L, k_{A} A$, and $k_{V} V$ are effective lengths, areas, and volumes, respectively; $S_{\text {Tens }}$ is applied tensile stress [ $=S$ in Eq. (1)]; $\sigma_{O L}, \sigma_{O A}$, and $\sigma_{O V}$ are length, area, and volume scaling parameters, respectively; and $m_{L}, m_{A}$, and $m_{V}$ are Weibull moduli for length, area, and volume distributions, respectively. The functions in Eqs. (3)-(5) are essentially numerically used by brittle structural component design and life prediction computer programs, such as CARES [4], to predict the reliability of any component based on the strength data from laboratory test coupons. Such an exercise has been completed for a hypothetical suite of TE devices [11].

Effective sizes for simple mechanical test coupons can be determined analytically [7]. Results from examples of these calculations are listed in Table 1 for a three-point bend configuration used to test skutterudite TEMats [12]. 
Table 1. Example of effective size calculations for three-point bend testing for a skutterudite [12]

(A fixture span $\left(S_{L}\right)$ of $8.0 \mathrm{~mm}$, specimen square cross section $(b=h) 1.5 \times 1.5 \mathrm{~mm}$, and Weibull modulus $(\mathrm{m})=5$ were used in the calculations.)

\begin{tabular}{ccc}
\hline Effective Size & Equation & for $\boldsymbol{m}_{\boldsymbol{i}}=\mathbf{5}$ \\
\hline $\begin{array}{c}\text { Effective Length } \\
L_{\text {eff }}=k_{L} \bullet L\end{array}$ & $\left(2 \cdot S_{L}\right) /\left(m_{L}+1\right)$ & $2.67 \mathrm{~mm}$ \\
Effective Area & \\
$A_{\text {eff }}=k_{A} \bullet A$ & $2 \cdot S_{L} \bullet(h+b) \cdot\left(m_{A}+2\right) /\left(4 \cdot\left(m_{A}+1\right)^{2}\right)$ & $2.33 \mathrm{~mm}^{2}$ \\
Effective Volume & & \\
$V_{\text {eff }}=k_{V} \bullet V$ & $b \cdot h \cdot S_{L} / 2 \cdot\left(m_{V}+1\right)^{2}$ & $0.25 \mathrm{~mm}^{3}$ \\
\hline
\end{tabular}

\section{RELEVANT MECHANICAL PROPERTIES, CHARACTERISTICS, AND TEST METHODS}

Elastic properties and tensile or flexure strength testing of TEMats are the focus of Section 3 because they are the most important parameters that represent how a TEMat will mechanically respond during service. Literature-reported measurements and relevant test methods are discussed. Lastly, other mechanical characteristics are described.

\subsection{ELASTIC MODULUS AND POISSON'S RATIO}

Elastic modulus and Poisson's ratio are two of the most fundamental mechanical and material properties describing a TEMat.

Elastic modulus is measured through a variety of techniques. A classical approach is to mechanically strain a material and measure the restraining stress; if the material is linear elastic, then the slope of their relationship is the elastic modulus. This test method requires a relatively large amount of material, and this often cannot be satisfied with relatively small-sized TEMat coupons or billets. Dynamic methods based on speed of sound measurements, impulse excitation [13], and resonance methods are experimentally simple to conduct and do not require large test coupons for elastic property measurement. Poisson's ratio can also be independently determined.

But these dynamic methods ultimately output a mechanical response from an infinitesimally small strain excitation that is then used to calculate elastic modulus and Poisson's ratio (and other elastic constants calculated from them such as shear or bulk moduli). If, and only if, the material is linear elastic up through the anticipated service conditions, then the elastic constants measured by dynamic means remain valid and usable. However, if the material has a nonlinear response between zero strain and the service strain, then a (classical mechanical) stress-strain response needs to be generated and used for design and reliability estimation, and the impulse excitation and resonant ultrasound spectroscopy (RUS) measurements must be deprioritized. Their use can cause a large overestimation of applied service stress [14], which in turn can negatively affect engineering design decision making. If an elastic modulus is accurately and validly measured mechanically at the range of the anticipated service strains, and its value is different from what impulse excitation or RUS generated, then the experimentalist should use the mechanically measured elastic constant values.

The literature provides a wealth of elastic property measurements involving TEMats [1, 15-32], and a listing of those measurements is provided in Appendix A for $\mathrm{Ca}_{3} \mathrm{CoO}_{4}$, half-Heuslers, LAST and PbTe, skutterudites, and $\mathrm{Zn}_{4} \mathrm{Sb}_{3}$, along with information on the test method used for the measurement. 


\subsection{TENSILE OR FLEXURE STRENGTH}

There are numerous strength-test methods available [33] to the experimentalist who is evaluating brittle materials. Strength, or the maximum stress where an identifiable failure has initiated or occurred, is not a material property of a brittle material; rather, it is a characteristic of a brittle material.

As discussed in Section 2, the measured tensile strength value depends on many different independent parameters that include

- direction of mechanical loading (tension or compression);

- dimensionality of loading (uniaxial, biaxial, or other multiaxial);

- amount of material being stress (strength-size-scaling);

- flaw types, flaw locations, and flaw size distributions; and

- material fracture toughness, which is a material property.

The flexure (or tensile) strength tests most commonly used with TEMats are uniaxial flexure testing (i.e., three-point bending, four-point bending) and equibiaxial flexure testing (e.g., ball-on-ring, ring-on-ring). Ball-on-ring and ring-on-ring testing are axisymmetric equivalents of three-point bending and four-point bending, respectively. Photos of three-point-bend and four-point-bend fixtures are shown in Fig. 5.
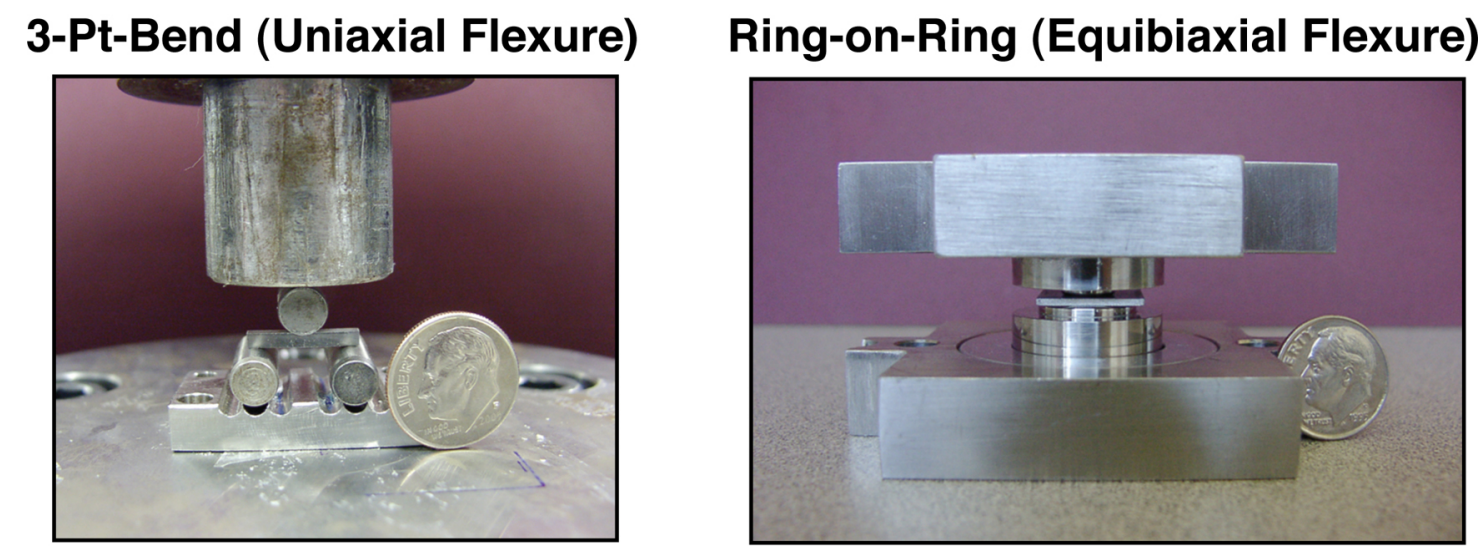

Fig. 5. Examples of uniaxial and biaxial flexure test figures used with thermoelectric strength testing.

\subsubsection{Uniaxial flexure testing}

It would be ideal if the cross-sectional sizes of potential TEMat legs were the same as specimens advocated for use in accepted test methods such as ASTM flexure test methods. ASTM C1161 [34] describes two specimen configurations whose cross-sectional dimensions $1.5 \times 2.0 \mathrm{~mm}$ and $3.0 \times 4.0 \mathrm{~mm}$ are similar to many TEMat leg sizes. ASTM F417 [35] (withdrawn 2001) advocated the use of a specimen whose cross-sectional dimensions were $2.0 \times 2.0 \mathrm{~mm}$. However, it is not a problem if the size of the TEMat leg dimensions is different from that of the ASTM flexure specimens. If custom-made uniaxial flexure testing fixtures (i.e., bend spans relative to specimen dimensions) are appropriately designed by the experimentalist to promote deflection adhering to classical beam bending theory and that also do not cause high-contact stresses at the rollers, then the use of non-ASTM flexure testing is still valid and completely acceptable.

There is a substantial amount of information on uniaxial flexure testing of TEMats in the literature [1, 12, $15,17,28,32,36-42]$, and a listing of uniaxial flexure strength values for bismuth tellurides, $\mathrm{Ca}_{3} \mathrm{CoO}_{4}$, 
half-Heuslers, $\mathrm{PbTe}$, skutterudites, and $\mathrm{Zn}_{4} \mathrm{Sb}_{3}$ is provided in Appendix $\mathrm{B}$, along with information on the test method used for the measurements.

Size-scaling theory is considered in two studies involving skutterudites $[1,12]$, which include a comparison of their strengths. Electrical discharge machined prismatic bars of $1.5 \times 2.0 \times 28 \mathrm{~mm}$ of n-type $\mathrm{CoSb}_{3}$ and p-type $\mathrm{CeFe}_{3-\mathrm{x}} \mathrm{Ru}_{\mathrm{x}} \mathrm{Sb}_{3}$ were flexure strength tested in Ref. [1]. The authors cite the general use of ASTM C1161 [33] and four-point bending but do not specifically state the flexure fixture size they used, though it is surmised that they used 10 and $20 \mathrm{~mm}$ spans. They report a characteristic strength of $91 \mathrm{MPa}$ for the n-type material and $40 \mathrm{MPa}$ for the p-type material. To enable a comparison to Ref. [12], Ravi et al.'s [1] results produce associated $k_{L} L=23.3 \mathrm{~mm}, k_{A} A=26.3 \mathrm{~mm}^{2}$, and $k_{V} V=2.9 \mathrm{~mm}^{3}$ (see Ref. [7] for $k_{A} A$ and $k_{V} V$ calculations for four-point bending). Using the general Weibull scaling form of $\mathrm{S}_{2}=(\text { effective size } 1 / \text { effective size } 2)^{1 / \mathrm{m}} \cdot \mathrm{S}_{1}$, and those results listed in Table 1, the failure stresses would be $\sim 50-60 \%$ higher for the skutterudites in Ref. [12] for the same probability of failure. This analysis suggests that the strength of the n-type materials in the two studies is equivalent but that the p-type material strength in Ref. [12] is higher.

Uniaxial flexure or tensile testing can be an effective means of determining whether strength anisotropy exists in TEMats. In one example, the tensile strength of bismuth telluride in a direction parallel to the axis of the processed cylindrical billets was different from its strength when the direction was perpendicular to the axis [39]. The identification of such anisotropy can enable the end user to pursue a strategy in which the stronger direction is purposely used in an orientation where the tensile stresses are higher in service, thus improving the probability of survival of the TEMat.

\subsubsection{Biaxial flexure testing}

Biaxial testing can come in many forms (e.g., torsion testing, torsion-axial testing, different combinations thereof) [33]; however, typically for the mechanical evaluation of brittle materials, equibiaxial testing (i.e., equal tensile stressing in orthogonal directions within the same plane) is normally pursued experimentally. For the sake of convenience, the "equi" prefix is normally dropped from the word "equibiaxial," so "biaxial flexure testing" for brittle materials is normally interpreted to mean equibiaxial stressing.

Biaxial flexure testing is a standardized test [43] and has an advantage over uniaxial flexure testing because it subjects the test coupon and its material and all potential strength-limiting flaw populations to a biaxial stress field. Almost all structural loadings in actual applications are multidimensional, including the multidimensional stress field in TE legs subjected to a temperature gradient. For the same effective size of a brittle material, the biaxial (tensile) failure stress will be lower than for the same magnitude of a uniaxial (tensile) failure stress, so for a conservative design, biaxial flexure data are often preferred. However, biaxial flexure testing has some disadvantages and can be an inappropriate test method if the way a brittle material is actually loaded in service is not accurately represented. The latter is arguably the case for TEMats.

Biaxial flexure testing necessitates the use and consumption of relatively large specimens. If the size of a processed billet of a brittle material cannot be fabricated into a large shape, thus enabling the harvesting of the relatively large test coupons, then the prospect for utilizing biaxial flexure testing diminishes or ends. Additionally, because stressing surveys a relatively large volume or surface area of the specimen, the specimen will almost always fail from the largest flaw. The identification of that largest flaw is normally viewed positively; however, for TEMats, these biaxial flexure disks are often cut and sliced into legs (uniaxial flexure bars), and that same large flaw may often cause a leg or uniaxial flexure bar to crack during slicing. This manifests itself in a useful mode of proof testing and ultimately removing that large flaw (and its surrounding) from the actual end-use population (as will be discussed later in this report). In 
this situation, biaxial flexure testing that is affected by that large flaw would yield a data point that is actually irrelevant.

Biaxial flexure testing has another disadvantage in the context of prismatically shaped TE legs. Unlike a prismatically shaped TE leg, there are no edges or corners in a biaxial flexure specimen. Therefore, failure stress of the biaxial flexure specimen can never be limited by the realistically active corner-type flaw that exists in a TEMat leg.

For any brittle material component design or its evaluation, it is preferred that one use a strength-test specimen whose geometry is the same as the final component (i.e., a prismatically shaped TEMat leg). It is actually rare for a materials scientist or engineer to have the ability to do that for brittle material applications; hence, if it is possible, one should take advantage of the opportunity.

For the case of prismatically shaped TE legs, the use of uniaxial flexure specimens, whose cross-sectional sizes are identical to the legs, is preferred. When the flexure specimens are mechanically loaded, volume-, surface- and edge-type flaws all have the potential to be strength limiting. These results are completely relevant for interpreting how a TEMat leg (of the same size and shape) will mechanical respond to service conditions.

There is some literature involving the biaxial flexure testing of TEMats [20, 24, 40, 44], and a listing of those biaxial flexure strength values is provided in Appendix $\mathrm{C}$ for bismuth telluride and LAST, along with information on the test method used for the measurement.

\subsection{OTHER MECHANICAL CHARACTERISTICS}

\subsubsection{Fracture toughness}

Fracture toughness is an important material property, and its relevancy to the mechanical response of a TEMat is illustrated in the Griffith equation in Eq. (1). There are three important unknowns in the Griffith equation, tensile stress or strength, flaw size, and fracture toughness. Tensile strength and flaw size are interrelated, and their functionality is linked to the fracture toughness. Fracture toughness can be estimated if the tensile strength and associated flaw size are quantified; however, there is not a unique combination of tensile strength and flaw size if only fracture toughness is known. In most brittle material practice, the fracture toughness for a given material does not vary significantly among grades of that material; however, strength (and flaw size) can vary substantially across grades of the "same" material. Therefore, for brittle materials, it is more informative to the brittle material developer and component designer to know the strength and flaw size than it is to know just fracture toughness, but obviously it is beneficial to know all three.

The valid measurement of fracture toughness can be a controversial topic, though it really does not need to be. There are three test methods outlined in ASTM C1421 [45] that have been proven to produce valid fracture toughness measurements. Any one of these three methods should be used when quantifying fracture toughness of a candidate TEMat. There are several studies involving $\mathrm{K}_{\mathrm{Ic}}$ measurement of TEMats that involve the use of one of the methods in ASTM C1421, and their reported values have legitimacy $[1,32,42,46]$. Among all those measurements and TEMats, the largest reported $\mathrm{K}_{\mathrm{Ic}}$ was $1.7 \mathrm{MPa} \sqrt{\mathrm{m}}$, although the majority of reported values were less than $1 \mathrm{MPa} \sqrt{\mathrm{m}}$. These low values indeed demonstrate that TEMats have a low fracture toughness and are brittle.

Controversy arises when Vickers indentation is used to report fracture toughness. This method does not produce a valid $\mathrm{K}_{\mathrm{Ic}}$ value [47]; unfortunately it continues to be used, probably due to its ease of measurement and misinterpretation or ignorance regarding the prerequisites needed to validly measure 
$\mathrm{K}_{\mathrm{Ic}}$. Vickers indentation should not be used to measure fracture toughness of TEMats. Several papers involving TEMats include the use of Vickers indentation and have reported $\mathrm{K}_{\mathrm{Ic}}$ values, but they are purposely not cited here to avoid creating the perception that these values are legitimate.

\subsubsection{Compressive strength}

The compressive strength (not a material property like tensile strength) of a TEMat is useful to know; however, compressive strength values are much larger than tensile strength values for the same material. Therefore, tensile (or flexure) strength measurements should be used for assessing a candidate TEMat or for generating data for device design or mechanical reliability analysis, as described earlier in this report. Compressive strength measurement is standardized [48], so there are at least a couple of studies where the compressive strength of a TEMat has been measured [1,49].

\subsubsection{Hardness}

Hardness is not a material property; rather, it is a characteristic of a material that is related to a material's yield strength, which is a material property. It is the deformation response of a material to a compressively loaded sharp or blunt hard indenter material. Deformation will be different for different shape indenters, different indenter materials, different maximum loads (i.e., indentation size effect), and different dwell durations. For brittle materials, Knoop [50] and Vickers [51] hardness indentation testing are the most common, with Knoop indentation tending to work better over a wider range of materials.

Hardness is a useful measurement in material development because it can be an effective indicator of how compressive deformation is affected by porosity or the material's microstructure and grain size. However, hardness results are not particularly useful for structural design of brittle material components when tensile-strength limitation is the primary concern and wear is not. Wear is not of particular concern for TEMats, so hardness measurements do not benefit the overall structural design of TE legs or TE devices. The literature indicates that TEMats are not particularly hard materials. Most reported values are less than $1 \mathrm{GPa}[15,20-21,26,32]$.

\subsection{THERMAL SHOCK AND GRADIENT}

One of the many challenges in fabricating reliable TE generators for waste heat harvesting applications is to ensure the mechanical integrity of the generator when subjected to a variety of stresses, including mechanical vibrations and thermal transients. According to the literature on brittle materials, the tendency of a material to sustain damage via thermal shock (a single thermal cycle) is treated by a series of thermal shock resistance parameters. However, information on thermal fatigue damage of brittle materials is relatively limited. Thus, often analysis of the propensity for thermal fatigue damage is actually done using thermal shock resistance parameters. Nevertheless, there are extremely significant differences between thermal shock and thermal fatigue, especially in terms of the microstructural response of the material, as shall be discussed at the end of this section.

Before dealing with the thermal shock resistance parameters, it is helpful to consider expressions for the stress induced in a solid due to a thermal transient. One can begin by solving the Fourier law of heat conduction for the time-dependent temperature distribution and then link the temperature distribution to the induced stress. While numerical techniques are needed for problems other than simple geometries, we shall outline the analytical solution for thermal-shock-induced stresses in an infinite flat plate of finite thickness. This approach is a natural way of introducing the material parameters that are important to thermal shock problems and demonstrating the origin of a number of the expressions in the literature (including the thermal shock resistance parameters) that are in fact approximations to the Fourier law solution [52-54]. 
While numerical methods are necessary for bodies with complex geometry, we will consider a onedimensional Cartesian coordinate form of the time-dependent Fourier law of heat conduction, which can be written as $[52-53,55]$

$$
\frac{\partial^{2} \mathrm{~T}(\mathrm{z}, \mathrm{t})}{\partial \mathrm{z}^{2}}=\frac{1}{\kappa_{\mathrm{z}}} \frac{\partial \mathrm{T}(\mathrm{z}, \mathrm{t})}{\partial \mathrm{t}}, \quad|\mathrm{z}| \leq \mathrm{H}
$$

where the spatial coordinate $\mathrm{z}$ is zero at the midplane of the plate and $\mathrm{z}= \pm \mathrm{H}$ at the external plate surfaces. In addition, $\mathrm{t}=$ time, $\mathrm{T}(\mathrm{z}, \mathrm{t})=$ temperature at position $\mathrm{z}$ and time $\mathrm{t}$, and $\kappa_{\mathrm{z}}=$ the plate's thermal diffusivity in the $\mathrm{z}$ direction. To solve Eq. (6), convective heat transfer conditions are typically assumed, giving the following solution for the temperature distribution in the plate:

$$
\frac{\mathrm{T}(z, t)-\mathrm{T}_{i}}{\mathrm{~T}_{i}-\mathrm{T}_{\infty}}=-1+2 \sum_{n=1}^{\infty} \frac{\sin \beta_{n} \cos \left(\beta_{n} z / H\right)}{\beta_{n}+\sin \beta_{n} \cos \beta_{n}} \exp \left(-\beta_{n}^{2} \frac{\kappa_{z} t}{H^{2}}\right)
$$

where $T_{\mathrm{i}}$ and $T_{\infty}$ are, respectively, the initial temperatures of the plate temperature and the cooling medium. The term $T_{i}-T_{\infty}$ is thus the "quench temperature difference," which occurs frequently in thermal shock literature. In addition, the coefficients $\beta_{n}$ in the infinite series in Eq. (8) are the roots of the equation $\beta \tan \beta=\mathrm{Bi}$, where $\mathrm{Bi}$ is the Biot modulus. $\mathrm{Bi}$ is in turn a dimensionless parameter given by $\mathrm{Bi}=\mathrm{ah} / \mathrm{k}$, where $\mathrm{k}$ is the thermal conductivity of the solid, $\mathrm{h}$ is the surface heat transfer coefficient, and a is the characteristic specimen dimension. For example, for the flat plate considered above, $a=H$, the halfthickness of the plate. Also, for a rod of radius $r$ or a sphere of radius $r, a=r$.

The physical significance of $\mathrm{Bi}$ in relation to thermal shock problems can be appreciated based on the fact that the surface heat transfer coefficient is related to the rate at which energy can move from the quench medium to the interface between the quench medium and the thermally shocked specimen. Also, $\mathrm{k}$ is a measure of the rate at which thermal energy can be transported within the solid. Thus, the Biot modulus, $\mathrm{Bi}$, gives a measure of the thermal energy transport across the interface, which is central to the evolution of the temperature distribution during the thermal transient event (thermal shock).

To move from the temperature distribution given by Eq. (7) to the thermally induced stresses, one can use force and moment equilibrium conditions to obtain [53]

$$
\frac{E \alpha \Delta T}{(1-v)}=2 \sum_{n=1}^{\infty} \frac{\sin \beta_{n}}{\beta_{n}+\sin \beta_{n} \cos \beta_{n}}\left\{\cos \left(\beta_{n} \frac{z}{\mathrm{H}}\right)-\frac{\sin \beta_{n}}{\beta_{n}}\right\} \exp \left(-\beta_{n}^{2} \frac{\kappa_{z} t}{H^{2}}\right)
$$

Now on the left-hand side of Eq. (8), some of the thermal and mechanical properties of the plate appear, namely, $\mathrm{E}=$ Young's modulus, $v=$ Poisson's ratio, and $\alpha=$ the linear CTE. In addition to the material properties, the quench temperature difference is $\Delta \mathrm{T}$, which was present as a normalization factor in the expression for temperature distribution. The maximum surface stress, $\sigma_{\max }$, is then approximated as [53, $55]$

$$
\sigma_{\max }=\frac{E(T)}{1-v(T)} \alpha(T) \cdot\left(T_{i}-T_{\infty}\right) \cdot f(B i)
$$


A number of relatively simple closed-form approximations for the function $\mathrm{f}(\mathrm{Bi})$ are available in the literature, such as the following relationship given by Manson [56]:

$$
\mathrm{f}_{\text {Manson }}(\mathrm{Bi})=(1.5+3.25 / \mathrm{Bi}-0.5 \exp (-16 / \mathrm{Bi}))^{-1} \text {. }
$$

To be able to consider fracture rather than just the stress distribution, one must consider the stress intensity factor, $\mathrm{K}$, which in turn is a function of the length of the preexisting cracks in the material. Again, for an infinite flat plate of thickness $\mathrm{H}$ containing a crack of length $\mathrm{c}$, the maximum stress intensity factor at the plate surface can be expressed as [57]

$$
\mathrm{K}_{\text {imax }}=\frac{E \alpha \Delta T \sqrt{c}}{1-v} f_{N o d a}(B i) \text {, }
$$

where $\mathrm{f}_{\mathrm{Noda}}(\mathrm{Bi})$ is approximated by a closed-form expression with terms involving the ratio of the crack length to the plate thickness and $\mathrm{E}, v, \alpha$, and $\Delta \mathrm{T}$ are as defined in Eq. (8).

This discussion has also identified several key parameters in the thermal shock process, namely, the mechanical properties $\mathrm{E}$ and $v$, the thermal properties $\alpha$ and $\mathrm{k}$, and the thermal energy transport parameter $\mathrm{Bi}$, which is in turn related to the dimensions of the shocked solid through the characteristic length a, as well as being a function of $k$ and the surface heat transfer coefficient $h$. Also, the initial thermal conditions of the quenched body and the quench medium are embodied in the quench temperature difference, $\Delta \mathrm{T}$. Thus, the parameters convey the complex interleaving of mechanical, thermal, and energy transport parameters that are encompassed by thermal shock.

The complex nature of thermal shock damage gave rise to two families of approximations that attempt to rank, rather than quantify, the ability of a material to withstand thermal shock damage. In 1955, Kingery [58] described thermoelastic thermal shock resistance parameters ( $R$ parameters) $R$ and $R$, which can be obtained as approximations to Eq. (9), namely,

$$
\begin{aligned}
& R=\frac{\sigma_{f}(1-v)}{E} \text { and } \\
& R^{\prime}=\frac{\sigma_{f} k(1-v)}{E} .
\end{aligned}
$$

One can obtain $\mathrm{R}$ from Eq. (9) by setting $\mathrm{f}(\mathrm{Bi})$ to unity. $\mathrm{R}$ can be derived from Eq. (9) by using the approximation $\mathrm{f}(\mathrm{Bi}) \sim \mathrm{Bi} / 3.25$, which is valid only for Bi small (very low quench rates) and then setting ha $=1[59]$.

During the 1960s, Hasselman introduced three additional R parameters, R , R , and $\mathrm{R}_{\mathrm{ST}}$, based on an energy balance approach. The Kingery and Hasselman R factors represent two different types of models, where the thermoelastic approach is based on the concept of resisting the propagation of cracks. In contrast to the thermoelastic approach, Hasselman's energy balance model assumes a body with multiple preexisting cracks. When a thermal shock occurs, many cracks extend simultaneously rather than as a single crack that fractures the body (in the thermoelastic approach). For a body containing an ensemble of short cracks, the energy balance approach yielded the thermal shock resistance parameters $\mathrm{R}$ and $\mathrm{R}$ such that 


$$
\begin{gathered}
R^{\prime \prime \prime}=\frac{E}{\sigma_{f}^{2}(1-v)} \text { and } \\
R^{\prime \prime \prime \prime}=\frac{E \gamma_{f}}{\sigma_{f}^{2}(1-v)} .
\end{gathered}
$$

The parameter $\mathrm{R}$ crack growth and $\mathrm{R}$ nucleation. can be considered to be the stored elastic strain energy at fracture available for as the minimum distance that a thermal-shock-induced crack propagates after

Note the differences in the role of the fracture strength in R and R [Eqs. (12)-(13)] as opposed to $\mathrm{R}$ and $\mathrm{R} \quad$ [Eqs. (14)-(15)]. In $\mathrm{R}$ and $\mathrm{R}, \sigma_{\mathrm{f}}$ is in the numerator, indicating that in those damage ranking systems it is advantageous to have the thermally shocked material as strong as possible so it resists the propagation of cracks. In $\mathrm{R} \quad$ and $\mathrm{R} \quad, \sigma_{\mathrm{f}}$ is in the numerator, indicating that it is not strength but the absorption of energy by the growth of multiple cracks that favors thermal shock resistance. Although each of the $\mathrm{R}$ factors deals with thermal shock rather than thermal fatigue, there are important links between the nature of $\mathrm{R}$ and $\mathrm{R}$ and microstructural aspects of the accumulation of thermal fatigue damage.

A critical consideration with respect to the fatigue damage of materials is that it has been shown that fatigue damage defeats the toughening mechanisms (such as grain bridging and crack face bridging by fibers or whiskers) [60-62]. Grain bridging, which is a highly effective toughening mechanism for a single loading cycle, leads to the destruction of grain contacts due to the repeated frictional loading during fatigue [60-62]. Likewise, toughening due to fiber and whisker pullout is negated during fatigue [60-62]. However, as reviewed by Case, intrinsic toughening mechanisms such as crack pinning by deflection by pores are not defeated by fatigue, and in fact, examples such as thermal barrier coatings and refractory bricks attest to the effectiveness of engineered porosity in resisting thermal fatigue [59]. Also, preexisting microcracks (and pores) lower the stored elastic strain energy available to drive macrocracks [54, 59]. Thus, in terms of the mechanical properties of TEMats and especially with regard to thermal fatigue, it is important to consider how pores and microcracks affect mechanical properties.

\section{MICROSTRUCTURAL ISSUES}

\subsection{RELATIONSHIP OF PROCESSING AND MICROSTRUCTURE}

In the study of materials, the connection between structure, properties, processing, and performance is fundamental, and the field of mechanical properties of TEMats certainly highlights these connections. By structure, we refer to macrostructure (size scale of millimeters and larger), microstructure, nanostructure, and atomic structure. For example, we shall later discuss the importance of structure as it relates to the mechanical properties of TEMats. We shall also discuss that while the macroscopic size and shape of a TE element affect the stresses generated during thermal transients, the microstructure (including the morphology and size of grains, pores, and microcracks) greatly affects how the material responds to an applied stress. Nanostructuring in TEMats has been very successfully used to decrease thermal conductivity via phonon scattering [63-64], but nanostructures can also affect mechanical properties in a number of ways. Atomic structure can impact isotropy, including thermal expansion anisotropy (TEA), which is a key mechanism associated with microcracking in brittle materials. 
With regard to processing, the details of the densification methods, time, temperature, and pressure are critical for setting the microstructure and nanostructure. While we will not focus on the processing techniques themselves, we will give examples of how processing can impact mechanical properties. Since a number of the common elements in TEMats have a tendency to sublimate at elevated temperatures, they can have an important impact on processing and the subsequent mechanical properties.

In terms of processing, it is crucial to note that powder processing and densification may give us the "starting" microstructure/nanostructure of the TEMats; however, the structure may evolve during exposure to in-service conditions of temperature and stress. That evolution can involve processes such as grain growth, creep, and either a decrease in porosity (densification) or increase in porosity (bloating). Also the extent of microcrack damage can either increase or decrease with time as a function of the inservice conditions. Thus, for the mechanical properties of TEMats, while processing sets the initial conditions, the properties are not necessarily static during use, and these changes can dramatically impact the performance and even viability of a given TEMat.

As the physical properties evolve, the performance also is subject to change. In the following sections, we shall focus on mechanical properties but we shall also briefly mention the trends in associated changes in thermal and electrical properties, since especially thermal and electrical conductivity directly impact ZT and hence TE performance. The functional forms for the thermal and electrical properties also help to emphasize some of the common trends among the structure, properties, processing, and performance for mechanical, thermal, and electrical properties of TEMats and other materials.

\subsection{POROSITY IN THERMOELECTRIC MATERIALS}

Porosity in TEMats can critically impact the mechanical properties of TEMats. We shall consider some of the mechanisms by which porosity occurs in TEMats and the implications of porosity for the mechanical properties. Mechanisms that can produce porosity in TEMats are as follows.

- Incomplete sintering from powders-While many TEMats are fabricated by casting from a melt, solidification of TEMats often produces large grain sizes. Large-grained materials are typically weak, and grain boundary scattering is much lower than in fine-grained materials (thermal conductivity). Thus, TEMats are often fabricated by grinding and milling ingots into a powder, followed by densification.

- Sublimation during densification-As will be discussed later in this section, many TEMats are subject to sublimation.

- Bloating of densified billets - This can lead to a change in physical properties during use, also potential loss of dimensional stability.

Porosity affects most electrical, thermal, and mechanical properties of brittle materials. Electrical properties that are functions of porosity include electrical conductivity [65-67], dielectric constant [6769], and dielectric breakdown strength [70-71]. Porosity-dependent thermal properties include thermal conductivity [65, 72-73] and thermal diffusivity [72-73]. In terms of mechanical properties, Young's modulus [74-77], shear modulus [74-76], fracture strength [78-80], fracture surface energy [81], and hardness [82] are all functions of porosity.

The mechanical properties of brittle materials are typically quite sensitive to porosity. A number of the property-porosity relationships in the literature have been expressed in terms of an exponential dependence on the volume, for porosity, P. For example, in the 1950s, an empirical 
expression for the fracture strength, $\sigma_{\mathrm{f}}$, of brittle materials as a function of volume fraction porosity, P, for brittle materials [83-84] was expressed as

$$
\sigma_{\mathrm{f}}=\sigma_{0} \exp \left(-\mathrm{b}_{\sigma} \mathrm{P}\right)
$$

where $\sigma_{0}$ is the fracture strength for the theoretically dense material and $b_{\sigma}$ is a unitless constant. In the 1960s an analogous relationship was presented for the P dependence of Young's modulus, E:

$$
\mathrm{E}=\mathrm{E}_{0} \exp \left(-\mathrm{b}_{\mathrm{E}} \mathrm{P}\right)
$$

where $\mathrm{E}_{0}$ is the Young's modulus for the theoretically dense material and $\mathrm{b}_{\mathrm{E}}$ is a unitless constant. As reviewed by Rice, the constants $b_{\sigma}$ and $b_{E}$ vary from material to material, but $b_{\sigma}$ typically ranges from about 2 to 6 for tensile fracture strength and roughly 3 to 18 for compressive fracture strength [85]. For the Young's modulus, $b_{\mathrm{E}}$ is typically between about 2 and 6 [85].

For both Young's modulus and strength, a number of relationships for porosity dependence have been proposed. In 1987 Phani and Niyogi proposed a semi-empirical equation [86]:

$$
\mathrm{E} / \mathrm{E}_{0}=(1-\mathrm{aP})^{\mathrm{n}} \text {. }
$$

For materials pressed from powder compacts, it has been shown empirically that the constant a in Eq. (18) may be equated to $1 / \mathrm{P}_{\mathrm{G}}$ (where $\mathrm{P}_{\mathrm{G}}$ is the porosity of the "green" or unfired compact).

Expanding Eqs. (16)-(18) in power series leads to a linear approximation of the form

$$
\mathrm{A}=\mathrm{A}_{0}\left(1-\mathrm{b}_{\mathrm{A}} \mathrm{P}\right)
$$

approximated well by linear equations in the limit of $\mathrm{P}$ small, a power series expansion of the functional forms given by Eqs. (16)-(17).

In addition to fracture strength and Young's modulus, an exponential or linear dependence on $\mathrm{P}$ has been observed for additional properties such as the as thermal conductivity [72], electrical conducity [85], dielectric constant [82], and hardness [82].

The mechanical property-porosity relationships given by Eqs. (16)-(17) assume that the pores are roughly equiaxed and homogeneously distributed within the bulk of the TEMat. In materials for which the pores are highly aligned, the mechanical properties can be strongly anisotropic [87-88]. However TEMats with aligned porosity are apparently not currently of practical interest.

\section{MATERIAL NONEQUILIBRIUM}

Successful structural design of brittle material components and their confident life prediction over a given service condition are predicated based on the material being in equilibrium (or in an "inert" state) throughout time under that service. In this context, equilibrium means that the initial and dominant populations of strength-limiting flaws remain dominant throughout service life, and that some serviceinduced change in the material state does not introduce new and dominant strength- or service-limiting flaw types (i.e., nonequilibrium). The preceding mechanical response discussions assume that the TEMat is in equilibrium.

Examples of nonequilibrium phenomena that compromise the inert mechanical state are discussed in the following section. Time- or service-dependent bloating and microcracking are two examples of a material 
not in equilibrium. If a material that is in equilibrium lapses into a nonequilibrium state, then representation of the compromised mechanical performance must be incorporated into the brittle material component's design and reliability prediction. However, this may not be a tractable endeavor because it can be difficult, if not impossible, to predict all the mechanisms that are associated with the potential onset of some nonequilibrium states that could become operative. If a material is in nonequilibrium during the life of its operation, then there is greater risk associated with its use. If possible, an alternative material that exhibits equilibrium should be considered instead for use.

A simple indicator of potential nonequilibrium initiation in a material (and the temperature at which it occurs) involves the use of a slow-heating rate [89] or soak-temperature dilatometry; if there is a change of rate of elongation, then that can be an indicator that the material is undergoing a change of state at a particular temperature (Fig. 6).

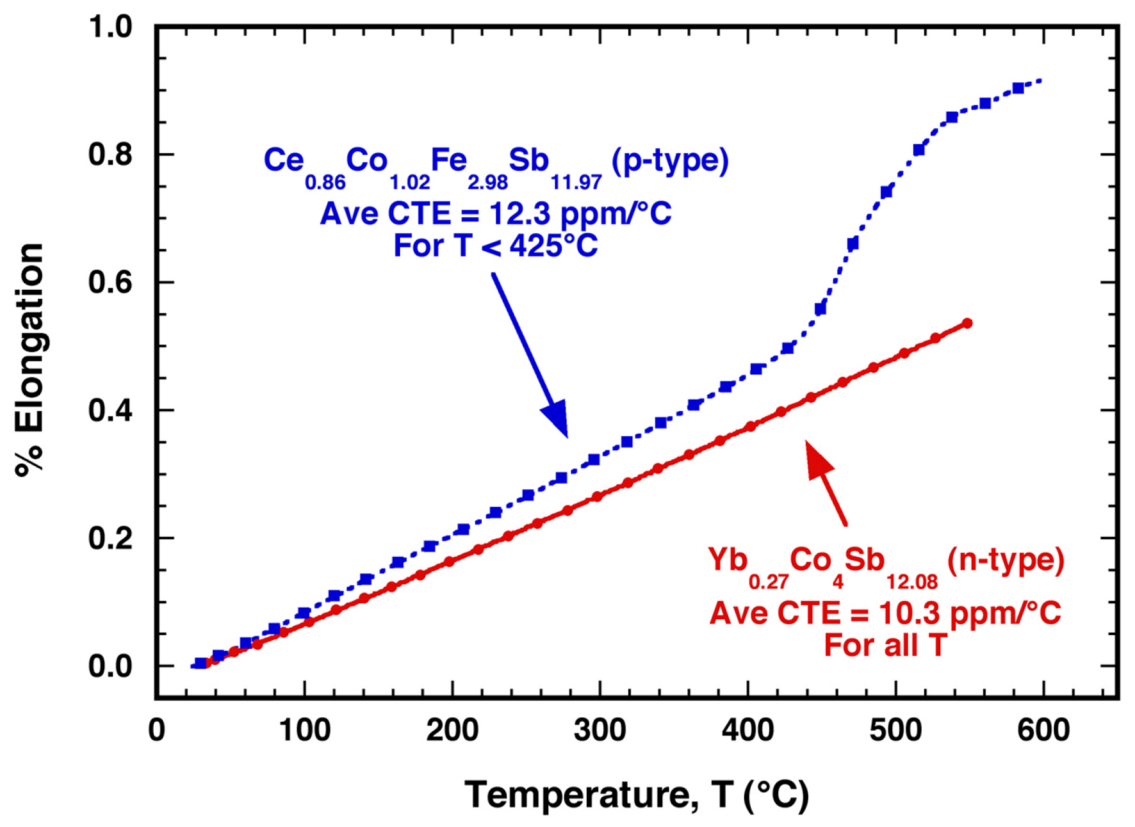

Fig. 6. Dilatometry can be an effective way to identify at what temperature a material may exhibit nonequilibrium and a change in mechanical response [12]. If this p-type skutterudite were mechanically tested above $400^{\circ} \mathrm{C}$, then its mechanical response could be much different from its response below $400^{\circ} \mathrm{C}$.

\subsection{BLOATING}

When TE specimens are densified under pressure, such as by hot pressing or pulsed electric current sintering (PECS), and then thermally annealed, porosity can be generated during the anneal [90-94]. This is likely related to bloating, a process in which a solid-phase decomposition reaction generates a gas phase internal to a material that results in localized creep, pore formation, and cracking [58, 95-98]. If bloating occurs in a TEMat, the solid-phase decomposition reaction likely involves sublimation. Also, if bloating does occur, the porosity generated by bloating can have significant effects on the mechanical, thermal, and electrical properties of the TE, as discussed in the previous section.

At elevated temperatures, sublimation rates have been observed to be significant for a broad range of TEMats, especially TEMats that include chalcogens (sulfur, tellurium, selenium, and oxygen), rare earth 
ions, and/or metals such as antimony and magnesium [99]. For example, Nesbitt et al. found a high rate of sublimation of dense hot-pressed $\mathrm{Yb}_{14} \mathrm{MnSb}_{11}$ TE due to ytterbium and antimony losses during annealing in a vacuum at $1,000^{\circ} \mathrm{C}[100]$. Lead-tellurium-based TEMats experience high sublimation due to tellurium ion losses [101].

When the sublimation rates are very high, weight loss and pore formation can occur during processing as well. For example, in PECS-processed TAGS [(AgSbTe $)_{(1-x)}(\mathrm{GeTe})_{\mathrm{x}}$, where $\mathrm{x}$ ranged from 0.80 to 0.90], sublimation was a very sensitive function of the processing pressure and heating rate [30], with considerable pore formation under some processing conditions. Also, for PECS-processed $\mathrm{Bi}_{2} \mathrm{~S}_{3}$, Ge et al. [102] observed extensive weight loss and pore formation at higher sintering temperatures, which they attributed to sublimation of both $\mathrm{Bi}$ and $\mathrm{S}$. Nesbitt et al. found a high rate of sublimation of dense hot-pressed $\mathrm{Yb}_{14} \mathrm{MnSb}_{11}$ TEMats due to ytterbium and antimony losses during annealing in a vacuum at $1,000^{\circ} \mathrm{C}[100]$.

For specimens that are dense or nearly dense in the as-sintered state, subsequent anneals in a vacuum or an inert atmosphere can lead to bloating and/or cracking. In a study by Zhao et al. [90], polished specimens of as-densified $\mathrm{CoSb}_{3}$ showed a crack-free and essentially pore-free surface. However, for $\mathrm{CoSb}_{3}$ specimens annealed in vacuum at $600^{\circ} \mathrm{C}$ for 8 days, both grain boundary cracking and pores appeared, with the pores roughly several microns in diameter. Annealing for 16 days at $600^{\circ} \mathrm{C}$ increased the number of grain boundary cracks along with the number and size of grain boundary porosity [90]. A vacuum anneal at $750^{\circ} \mathrm{C}$ for 16 days produced surface blisters that were greater than $500 \mu \mathrm{m}$ in diameter, with cracks in the dome of the blister that were also several hundred microns in length. Zhao et al. [90] attributed the cracking, porosity, and surface blistering to the sublimation of antimony during annealing.

In addition to the degradation of $\mathrm{CoSb}_{3}$, for $\mathrm{p}$-type $\left(\mathrm{Bi}_{0.2} \mathrm{Sb}_{0.82} \mathrm{Te}_{3}\right)$ powders sintered in a multimode microwave cavity, Hak et al. [91] observed bloating where "the final relative density reaches an upper limit of $86 \%$ due to the formation of Te gas, which results in closed porosity." Also, similar pore formation attributed to tellurium sublimation has been observed upon annealing of dense spark plasmasintered n-type $\mathrm{Bi}_{2} \mathrm{Te}_{3}$ [103] in an oxygen-free atmosphere for $10 \mathrm{~h}$ at temperatures of $523 \mathrm{~K}$ and $593 \mathrm{~K}$.

In a study of the temperature-dependent thermal expansion of hot-pressed p-type $\mathrm{Ce}_{0.9} \mathrm{Fe}_{3.5} \mathrm{Co}_{0.5} \mathrm{Sb}_{12}$ and n-type $\mathrm{Co}_{0.95} \mathrm{Pd}_{0.05} \mathrm{Te}_{0.05} \mathrm{Sb}_{3}$ skutterudites, Schmidt et al. observed pore formation due to bloating (Fig. 7) when densified specimens were annealed at temperatures in excess of $600 \mathrm{~K}$ [92]. Also, in studies of $\mathrm{PbTe}-\mathrm{PbS}$ TE specimens by $\mathrm{Ni}$ et al. [93-94], annealing densified specimens at temperatures $>543 \mathrm{~K}$ induced changes in both Young's modulus [93] and thermal expansion [94] that were consistent with bloating. In addition, scanning electron microscope (SEM) micrographs of fracture surfaces of the $\mathrm{PbTe}-\mathrm{PbS}$ taken before and after thermal annealing showed that a dramatic increase in porosity occurred during annealing [93, 104].
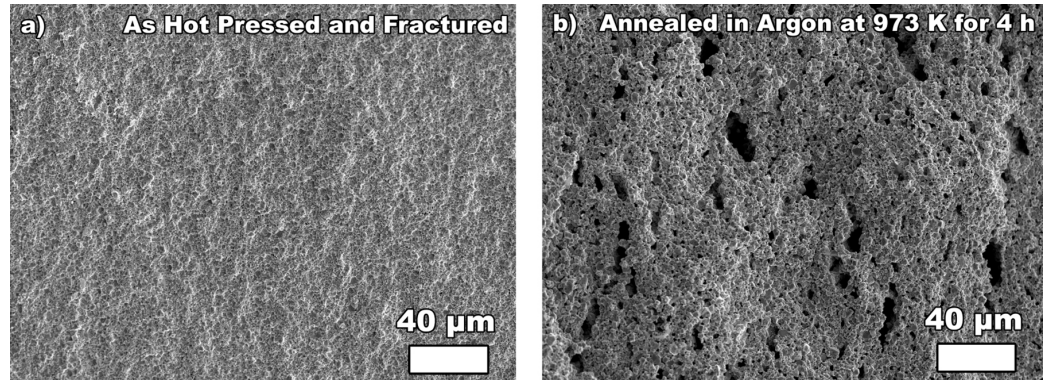

Fig. 7. For a $\mathrm{Co}_{0.95} \mathrm{Pd}_{0.05} \mathrm{Te}_{0.05} \mathrm{Sb}_{3}$ specimen hot pressed at $793 \mathrm{~K}$ at 74.4 MPa maximum pressure, (a) a fracture surface of the specimen as a hot-pressed specimen and (b) a fracture surface of the 
same specimen, annealed at $973 \mathrm{~K}$ for $4 \mathrm{~h}$ in an argon atmosphere.

Note the bloating-induced increase in porosity for the annealed specimen.

For the alloy Ti-6V-4Al, bloating has been used to optimize the porosity needed for bone in-growth for biomedical applications [97-98]. Dunand and coworkers hot pressed Ti-6V-4Al powders in sealed metal canisters that had been back filled with argon gas [97-98]. The as-hot-pressed specimens were nearly $100 \%$ dense, but post-densification thermal anneals at temperatures of up to $1,000^{\circ} \mathrm{C}$ yielded porous specimens with up to 0.50 volume fraction porosity, where the total porosity and pore size could be engineered by adjusting the annealing temperature and time. Dunand et al. proposed that localized creep was the likely bloating mechanism [95-98] for Ti-6V-4Al and in earlier work on bloating in titanium. Localized creep is a feasible explanation for the bloating in TEMats as such creep processes would be prone to a combination of deformation at cracking at lower temperature.

During processing one can attempt to minimize the effects of sublimation by adjusting process variables such as the sintering temperature or heating rate [30]. However, when bloating occurs in already-densified specimens, problems arise if the temperature for the onset of significant bloating is within the useful temperature range for the TE. The porosity induced by bloating changes the mechanical properties and thermal expansion coefficient [92-94, 104], and bloating leads to a loss of dimensional stability of the TE elements. For example, an isotropic volume change due to bloating would change both the leg length and the area of the leg bonded to the TE interconnections. Also, the in-service time at temperature will be many times longer than the sintering time, leading to the possibility that significant sublimation (and hence bloating) could occur at significantly lower temperatures during annealing than during sintering.

In some cases, the choice of densification method can mitigate post-densification bloating. Comparing $\mathrm{PbTe}-\mathrm{PbS}$ densified by hot pressing and by PECS, Ni et al. [93, 104] found that the specimens densified by hot pressing did bloat upon thermal annealing while the specimens densified by PECS did not. Ni et al. $[93,104]$ suggested that the elimination of the bloating in PbTe-PbS via PECS processing may be related to reported PECS cleaning of surface contaminants from powders during densification [105-107]. However, for PECS-processed SnTe TE specimens, post-densification annealing did result in bloating (Fig. 8). Thus, PECS processing can mitigate post-densification bloating in some but not all TEMats.
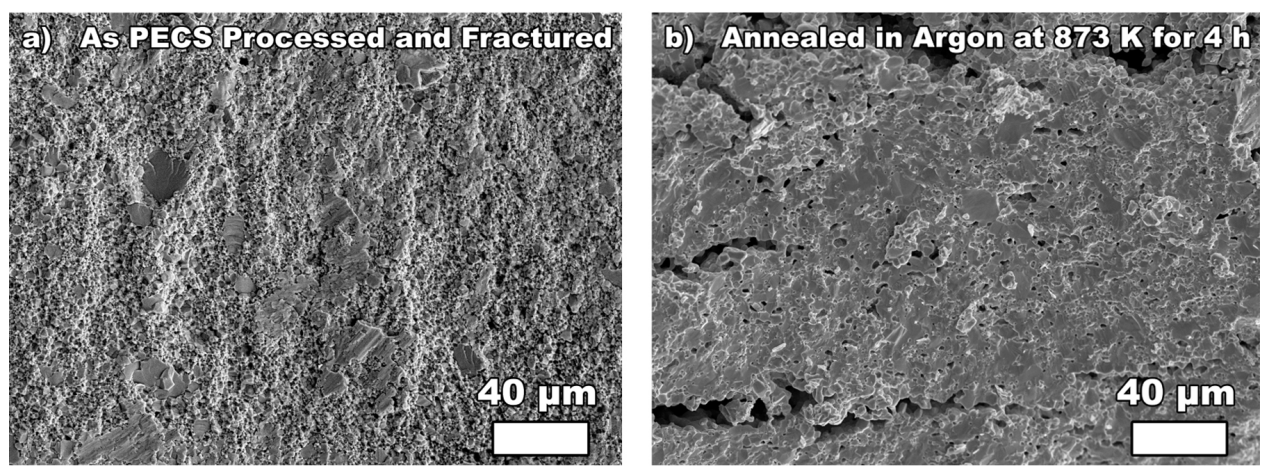

Fig. 8. For a pulsed electric current SnTe specimen sintered at $673 \mathrm{~K}$ with a maximum pressure of $60 \mathrm{MPa}$, (a) a fracture surface of the as-densified specimen and (b) a fracture surface of the same specimen following annealing in argon at 873 K. As in Fig. 7, the thermal anneal led to a significant increase in porosity.

\subsection{MICROCRACKING}

As is the case with porosity, microcracking influences a broad spectrum of physical properties such as elastic modulus [108-112], Poisson's ratio [112-113], and fracture strength [114-115]. In addition, 
electrical and thermal properties, including electrical conductivity [116-119] and thermal conductivity $[120,121]$, change with accumulating microcrack damage.

It is not enough to say "microcracking happens." To understand the context within which microcracking occurs, it is important to be aware of the various mechanisms that can induce microcracking. Knowledge of these mechanisms then gives us insight, for example, into (1) possible ways to avoid microcracking via changes in processing and (2) how and when microcrack damage can be mitigated. If the maximum temperature is sufficiently high, microcracks can diffusively heal. However, whether this healing is permanent or whether the microcracks reappear on thermal cycling depends on the microcracking mechanism, as will be discussed below.

Two microcracking mechanisms that are treated extensively in the literature for brittle materials are martensitic-type phase transformations and TEA. Martensitic phase transformations are characterized by rapid displacive shifts in the lattice parameter of a material accompanied by a significant (on the order of at least a few volume percent) change in the unit cell volume. These types of transformations are responsible for the toughening effects in zirconia-containing systems [122]. However, martensitic transformations have not been documented for TEMats that are potential candidates for waste-heatrecovery applications.

TEA is present for single-phase materials when the thermal expansion coefficients of a material differ along at least two of the crystallographic axes. For neighboring grains, TEA leads to differing rates of expansion (or contraction) as a function of direction, which generates internal stresses that can result in microcracking [111, 123-125]. Since thermal expansion is described by a second rank tensor [126], TEA only applies to materials with lower symmetry than cubic. (Physical properties expressed as second rank tensors, such as thermal conductivity, electrical conductivity, and thermal expansion, are isotropic in cubic materials but anisotropic in all systems with lower symmetry [126].)

Thus, TEA as a microcracking mechanism does not apply to the many TEMats that crystallize in cubic symmetry such as most chalcogenides, skutterudites, and $\mathrm{Mg}_{2} \mathrm{Si}$-based materials. However, layered TEMats such as $\mathrm{Bi}_{2} \mathrm{Te}_{3}$-based and cobaltates are of hexagonal or lower symmetry and thus in principle are candidates for microcrack damage due to TEA. However, whether a given single-phase crystalline material exhibits microcracking due to TEA is a function of the grain size of the material. The grain size dependence for microcracking due to TEA can be derived using an energy balance model in which the three-dimensional stored elastic strain energy is converted into a two-dimensional crack surface energy [125] with

$$
\mathrm{G}_{\mathrm{c}}=\frac{14.4 \gamma_{\mathrm{f}}}{\mathrm{E}(\delta \mathrm{T})^{2}\left(\Delta \alpha_{\max }\right)^{2}}
$$

where $G_{C}$ is the critical grain size for microcracking, $\gamma_{f}$ is the fracture surface energy, $E$ is the Young's modulus of the uncracked material, and $\Delta \alpha_{\max }$ is the maximum difference in the thermal expansion coefficients along the crystallographic axes. For cubic materials, $\Delta \alpha_{\max }=0$. A highly anisotropic material, $\mathrm{Al}_{2} \mathrm{TiO}_{5}$, has a $\Delta \alpha_{\max } \approx 24.1 \times 10^{-6} \mathrm{~K}^{-1}$ [127] with a critical grain size, $\mathrm{G}_{\mathrm{C}}$, for microcracking due to TEA on the order of $1 \mu \mathrm{m}$. In contrast, for alumina, where $\Delta \alpha_{\max } \approx 1 \times 10^{-6} \mathrm{~K}^{-1}$ [128], the critical grain size is about $70 \mu \mathrm{m}$ [128-129]. Therefore, for $\mathrm{Al}_{2} \mathrm{TiO}_{5}$, one must achieve a grain size less than $1 \mu \mathrm{m}$ to avoid microcracking due to TEA, while alumina specimens with grain sizes smaller than $70 \mu \mathrm{m}$ do not microcrack.

Thus, for a given material, it is possible to avoid microcracking due to TEA by refining the grain size sufficiently. Because TEMats typically are processed with submicron to nanometer grain sizes to take 
advantage of phonon scattering by grain boundaries, this may also avoid microcracking due to TEA in most cases.

Related to TEA is thermal expansion mismatch, which refers to differences in the CTEs of two different phases. While many TEMats have been developed that include nanoparticles, the size of the nanoparticles is small enough that they are unlikely to generate microcracks. However, in TEMats, the thermal expansion mismatch between the TE elements and the module interconnects should be minimized by an appropriate selection of the materials [130-131].

For TEMats, additional mechanisms that can induce microcracks in materials are ones involving intermediate- or long-range stress fields [54]. Intermediate-range stresses include "point contact" sources such as indentation, cutting, or grinding. Long-range stress fields (that typically scale with the specimen dimensions) include external mechanical loading and thermal shock or fatigue.

In contrast to the long- and intermediate-range stress mechanisms that generate microcracks, the shortrange stress mechanisms (TEA and phase transformation, for example) are intrinsic mechanisms. The distinction between extrinsic and intrinsic microcracking mechanisms is very important in that for microcracking generated by external stresses, one can anneal the specimen and diffusively heal the microcracks, and upon slow cooling, the cracks do not reappear as long as the external stresses are no longer present. However, if one anneals specimens that microcrack due to TEA and phase transformations, while the microcracks can diffusively heal if heated to sufficiently high temperatures, the microcracks reopen upon cooling because the mechanism that originally generated the microcracks is still present in the material [54]. The temperature required for diffusive healing of microcracks can be estimated for a given material as $0.6 \mathrm{~T}_{h}$, where $T_{h}$ is the temperature of interest normalized by the melting point temperature [54], which is consistent with the general guideline that mass diffusion is an effective mass transport mechanism for $\mathrm{T}_{\mathrm{h}}$ of about 0.6 or greater. Thus the question of whether or not a microcrack can be permanently healed after thermal annealing depends on the nature of the mechanism that generates the microcracks.

Given the above discussion, in TEMats microcracks generated by cutting and grinding procedures should be subject to healing via an appropriate thermal treatment. As an example of microcrack healing in brittle materials, the square corners of multilayer ceramic capacitors are often tumbled with a medium to round their square corners [132], but the tumbling process can result in cracking and a loss of mechanical strength [133-134]. However, thermal annealing of the tumbled capacitors can restore mechanical strength [134]. While it has been suggested that chamfering to the edges of TE legs could both relieve the stress concentration due to sharp corners and (ideally) remove microcracks induced by cutting operations [135], the chamfering process itself may introduce crack damage. Thermal annealing the specimens in an inert atmosphere at $\mathrm{T}_{\mathrm{h}} \approx 0.6$ could diffusively heal and strengthen the legs.

Recent examples in the TE literature in which processing-related long-range stresses are associated with microcracking include work on CoSi-based materials by Sun et al. [116-117]. For example, Sun et al. [117] found that arc-melted CoSi specimens fractured during either cooling or cutting of the ingot into specimens. However, doping the CoSi with boron eliminated the microcracking problem. Sun et al. [117] demonstrated that in the boron-doped CoSi the boron was segregated to a grain boundary phase and assumed that the boron-rich grain boundary phase aided in the microcracks healing process, thus increasing the electrical conductivity of the specimens. In subsequent research by Sun et al. [116], $\mathrm{Co}_{1-\mathrm{x}} \mathrm{Rh}_{\mathrm{x}} \mathrm{Si}_{0.98} \mathrm{~B}_{0.02}$ specimens were again prepared by arc melting and again the electrical conductivity was maintained. Although a microcracking mechanism was not directly postulated by Sun et al. [116117], presumably the fracture occurred due to thermal transients during cooling of the arc-melted ingot. 
In another example of processing-related microcracking in TEMats, Rogl et al. [118] used a high-pressure torsion technique to fabricate an n-type skutterudite, $\mathrm{Sr}_{0.07} \mathrm{Ba}_{0.07} \mathrm{Yb}_{0.07} \mathrm{Co}_{4} \mathrm{Sb}_{12}$, that results in specimens with extensive plastic deformation, which is manifest in dislocations and microcracks. Upon thermal cycling between $300 \mathrm{~K}$ and about $700 \mathrm{~K}$, the thermal expansion of the skutterudite specimens showed a hysteresis that decreased from cycle to cycle for three thermal cycles. In addition, the electrical resistivity also decreased at temperatures above $550 \mathrm{~K}$. Rogl et al. attributed this behavior to the thermal annealing of dislocations and microcracks induced by the high-pressure torsion processing. This hysteresis in thermal expansion due to microcrack healing is consistent with the behavior reported for a variety of brittle materials.

In addition to the nature of the physical mechanisms that lead to microcracking damage, additional insight can be gained from considering models for the relative change in physical properties as a function of microcrack damage. For example, the change in Young's modulus, E, for a microcracked material can be written as

$$
E=E_{0}\left(1-f_{E}(v) \varepsilon\right)
$$

where $\mathrm{E}_{0}$ is the Young's modulus of the unmicrocracked state. The function $\mathrm{f}_{\mathrm{E}}$ depends on the relative microcrack alignment and is also a weak function of the Poisson's ratio. The crack damage parameter $\varepsilon$ [136-137] in turn is a function of $\mathrm{N}$, the crack perimeter and the crack area. For circular cracks of radius a, the expression for the crack damage parameter becomes $\varepsilon=\mathrm{N}<\mathrm{a}^{3}>$, where $<\mathrm{a}^{3}>$ is the third moment of the crack size distribution. If all of the microcracks have the same radius, then $\varepsilon$ simplifies further to $\mathrm{Na}^{3}$.

It is important to note that while the elastic modulus is a function of $\varepsilon$; the microcrack orientation; and Poisson's ratio, $v$, the microcrack-induced changes in the electrical and thermal conductivities may be written as [138-139]

$$
\begin{gathered}
\sigma_{\mathrm{e}}=\sigma_{\mathrm{e}_{0}}(1-\mathrm{g} \varepsilon) \text { and } \\
\mathrm{k}=\mathrm{k}_{0}(1-\mathrm{h} \varepsilon),
\end{gathered}
$$

where $\mathrm{g}$ and $\mathrm{h}$ are again functions of the crack orientation.

As one might expect, at a fixed concentration of microcracks, the magnitudes of the microcrack-induced changes in, say, thermal or electrical conductivity are functions of both (a) the relative orientation of the microcracks and (b) the microcrack orientation with respect $\mathrm{J}_{\mathrm{el}}$ or $\mathrm{J}_{\mathrm{th}}$, the fluxes of the electrical and thermal currents, respectively. In practice, the alignment of microcracks can depend on the nature of the applied stress field, such as damage produced by a grinding wheel on a brittle material [140] or material texturing (preferred grain orientation) of an anisotropic material [141]. Thus, TEMats that have been prepared using a grinding wheel or are composed of highly oriented, anisotropic grains might have microcrack damage in the form of aligned or partially aligned microcracks. Such aligned microcracks would be expected to contribute to the overall anisotropy in mechanical, thermal, and electrical properties of the material.

Three recent papers deal with the thermal fatigue of TEMats, and each of the three uses a different technique for thermal cycling the TE specimens [24, 94, 142]. Since in nearly every study of thermal shock and thermal fatigue of brittle materials in the literature a fluid quench medium (most often water but sometimes oil or air) is used, Ni and Case [94] quenched a cast LAST specimen in water at $\Delta \mathrm{T}=$ $50 \mathrm{~K}$, a hot-pressed LAST specimen in water at $\Delta \mathrm{T}=55 \mathrm{~K}$, and a second hot-pressed LAST specimen in 
silicone oil at $\Delta \mathrm{T}=50 \mathrm{~K}$. The thermal fatigue damage was monitored by elastic modulus measurements performed on the as-sintered specimens and following each thermal cycle. For the LAST specimens quenched in water, the change in Young's modulus as a function of the number of thermal fatigue cycles was well described by

$$
E(N)=E_{0}-\left(E_{0}-E_{\mathrm{SAT}}\right)\left\{1-\exp \left(-\beta\left(N-N_{\text {onset }}\right)\right\} \text { for } N \geq N_{\text {onset }},\right.
$$

where $E_{0}$ is the undamaged Young's modulus, $E_{\mathrm{SAT}}$ is the steady-state value of $E, \beta$ is a rate constant, $N$ is the number of thermal fatigue cycles, and $N_{\text {onset }}$ is the number of thermal shock cycles at which the decrement in $E$ can be detected [54]. For the LAST specimen quenched in silicone oil, no drop in $\mathrm{E}$ as a function of time was observed due to the much lower value of the heat transfer coefficient, $h$, and hence a lower Biot modulus, the thermally induced stresses were much lower for the silicone oil quench than for the water quench [Eq. (9)]. As reviewed by Case, Eq. (24) can well describe the thermal fatigue behavior for brittle metals, plastics, and ceramics quenched in a liquid or in air [54]. While the fluid quench approach used by $\mathrm{Ni}$ and Case [94] does not mimic the in-service thermal environment expected for TEMats, it does demonstrate that when quenched in the same manner as other brittle materials in the literature, the evolution of thermal fatigue damage [Eq. (24)] in the TE LAST is similar to that observed for other brittle materials.

Morrison et al. [24] performed a thermal fatigue study of n-type LAST and p-type LASTT (leadantimony-silver-tellurium-tin) in a test chamber that attempted to simulate in-service thermal conditions for TE elements. Disc-shaped LAST and LASTT specimens $25 \mathrm{~mm}$ in diameter and $2.5 \mathrm{~mm}$ thick were thermally fatigued for up to 200 thermal cycles in a test chamber that used a cooled copper block to hold the cold side temperature at $313 \mathrm{~K} \pm 4 \mathrm{~K}$ [24]. Using planar resistance heaters, the hot-side temperature was ramped up from $323 \mathrm{~K}$ to $673 \mathrm{~K}$ in about $9 \mathrm{~min}$. The power to the heaters was then turned off and the specimens cooled to $323 \mathrm{~K}$ in about $40 \mathrm{~min}$. Groups of 10 specimens each were fractured in a ring-onring configuration in the as-sintered state and following 30,60, 90, 120, 150, or 200 thermal cycles. For both LAST and LASTT, the mean $\sigma_{\mathrm{f}}$ was about $30 \mathrm{MPa}$ in the as-sintered condition. For LASTT, the $\sigma_{\mathrm{f}}$ was relatively constant in a band from about 25 to $40 \mathrm{MPa}$ for zero through 200 thermal fatigue cycles. For LAST, $\sigma_{\mathrm{f}}$ was relatively constant for the specimen groups tested at zero, 30 , and 60 thermal cycles, while $\sigma_{\mathrm{f}}$ increased and the scatter in strength increased for 90,120 , and 150 thermal cycles. However, the $\sigma_{\mathrm{f}}$ for LAST surprisingly recovered to roughly the zero cycle level for 200 cycles. The apparent recovery in strength for the specimens fatigued for 200 cycles may indicate that two competing mechanisms are at work, one being that of the damage induced by repeated thermal transients and the second related to limited crack healing since following each temperature up-ramp was a cooling period that lasted for $40 \mathrm{~min}$. The maximum temperature of $673 \mathrm{~K}$ during thermal cycling corresponds to a homologous temperature of about 0.55 [24]; thus, some partial microcrack healing may have occurred. A possible implication of partial healing is that during application, if TE generators are held near their maximum temperatures for long periods of time (several hours or longer), partial microcrack healing might also occur. However, even if it did occur, it is not certain how microcrack healing during in-service conditions might impact the long-term durability of a TE generator.

Barako et al. [142] thermally fatigued a TE module by subjecting it to a square wave voltage signal that cycled the temperature of one face of the module between $146^{\circ} \mathrm{C}$ and $-20^{\circ} \mathrm{C}$ over a period of $60 \mathrm{~s}$. The other face of the module was maintained at $23^{\circ} \mathrm{C}$. After 45,000 thermal cycles, the module's ZT and electrical conductivity decreased by about a factor of 30 , but ZT and electrical conductivity for the module began to decrease rapidly after about 10,000 thermal cycles. Infrared microscopy of the module indicates that the temperature distribution changed as a function of thermal cycling, with nonparallel isotherms along the TE legs and hot areas evolving near the interfaces between the interconnects and the TE leg material. SEM examination of the interfaces revealed pores and cracks. Although the authors did not suggest it, the pores that were observed after thermal fatigue cycling may have been due in part to 
bloating mechanisms and in part to spalling of near-surface material by the link-up of microcracks. Also, the micrographs and thermal images given by the authors show the exterior surfaces of the TE legs and interconnect regions, but the authors do not mention post-test examinations of the interior of TE legs, where fractured surfaces might reveal whether or not bloating took place within the bulk of the TE material. However, the accelerated thermal fatigue testing of a TE module by Barako et al. shows that device failure from a TE standpoint can result from the evolution of thermal fatigue damage (in the form of microcracks and pores) in the TE legs and interconnect regions.

\section{REFERENCES}

[1] V. Ravi, S. Firdosy, T. Caillat, B. Lerch, A. Calamino, R. Pawlik, M. Nathal, A. Sechrist, J. Buchhalter, and S. Nutt, "Mechanical Properties of Thermoelectric Skutterudites," CP969, Space Technology and Applications International Forum - STA1F 2008, Ed. M. S. El-Genk, American Institute of Physics, 2008.

[2] S. F. Duffy, L. A. Janosik, A. A. Wereszczak, B. Schenk, A. Suzuki, J. Lamon, and D. J. Thomas, "Life Prediction of Structural Components," Ceramic Gas Turbine Component Development and Characterization, Edts. M. van Roode, M. K. Ferber, and D. W. Richerson, ASME Press, New York, NY, 2003.

[3] N. N. Nemeth, L. M. Powers, L. A. Janosik, and J. P. Gyekenyesi, "CARES/LIFE Ceramic Analysis and Reliability Evaluation of Structures Life Prediction Program," NASA/TM-2003106316, NASA Center for Aerospace Information, Hanover, MD, February 2003.

[4] CARES (Ceramic Analysis and Reliability Evaluation of Structures) Software, Connecticut Reserve Technologies, Gates Mills, OH.

[5] Standard Practice for Fractography and Characterization of Fracture Origins in Advanced Ceramics, ASTM C 1322, ASTM International, West Conshohocken, PA.

[6] Standard Practice for Reporting Uniaxial Strength Data and Estimating Weibull Distribution Parameters for Advanced Ceramics, ASTM C 1239, ASTM International, West Conshohocken, PA.

[7] Standard Practice for Size Scaling of Tensile Strengths Using Weibull Statistics for Advanced Ceramics, ASTM C 1683, ASTM International, West Conshohocken, PA.

[8] A. A. Griffith, "The Phenomena of Rupture and Flow in Solids," Philosophical Transactions of the Royal Society A, 221:163-198 (1921).

[9] Standard Test Method for Effect of Surface Grinding on Flexure Strength of Advanced Ceramics, ASTM C 1495, ASTM International, West Conshohocken, PA.

[10] WeibPar Software, Connecticut Reserve Technologies, Gates Mills, OH.

[11] O. M. Jadaan and A. A. Wereszczak, "Probabilistic Mechanical Reliability Prediction of Thermoelectric Legs," ORNL-TM-2009/133, U.S. Department of Energy, 2009.

[12] A. A. Wereszczak, M. E. Ragan, K. T. Strong, Jr., P. J. Ritt, H. Wang, J. R. Salvador, and J. Yang, "Strength of N- and P-Type Skutterudites," Ceramic Enginering and Science Proceedings, 9 31:49-60 (2010).

[13] Standard Test Method for Dynamic Young's Modulus, Shear Modulus, and Poisson's Ratio by Impulse Excitation of Vibration, ASTM E 1876, ASTM International, West Conshohocken, PA. 
[14] A. Wereszczak, E. Fox, M. Lance, and M. Ferber, "Failure Stress and Apparent Elastic Modulus of Diesel Particulate Filter Ceramics," SAE International Journal of Materials and Manufacturing, 5:517-527 (2012).

[15] D. Kenfaui, D. Chateigner, M. Gomina, J. G. Noudem, "Texture, Mechanical and Thermoelectric Properties of $\mathrm{Ca}_{3} \mathrm{Co}_{4} \mathrm{O}_{9}$ Ceramics," Journal of Alloys and Compounds, 490:472-479 (2010).

[16] Y. Kawaharada, K. Kurosaki, H. Muta, M. Uno, and S. Yamanaka, "Thermophysical Properties of $\mathrm{NiZrSn}_{1-\mathrm{x}} \mathrm{Sb}_{\mathrm{x}}$ half-Heusler Compounds," Journal of Alloys and Compounds, 381:9-11 (2004).

[17] S. Hirono, M. Okamura, F. Kawashima, "Thermoelectric Conversion Module, and Heat Exchanger, Thermoelectric Temperature Control Device and Thermoelectric Generator Employing the Same," US Patent 2010/0193001, 2010.

[18] J. Germond, "Structural Characterization and Thermoelectric Performance of ZrNiSn HalfHeusler Compound Synthesized by Mechanical Alloying," MS Thesis, University of New Orleans, 2010.

[19] F. Ren, E. D. Case, E. J. Timm, and H. J. Schock, "Young's Modulus as a Function of Composition for an N-Type Lead-Antimony-Silver-Telluride (LAST) Thermoelectric Material," Philosophical Magazine, 87:4907-4934 (2007).

[20] F. Ren, B. D. Hall, J. E. Ni, E. D. Case, J. Sootsman, M. G. Kanatzidis, E. Lara-Curzio, R. M. Trejo, and E. J. Timm, "Mechanical Characterization of PbTe-Based Thermoelectric Materials," Materials Research Society Symposium Proceedings Volume 1044, Paper 1044-U0404 (2008).

[21] F. Ren, E. D. Case, B. D. Hall, J. E. Ni, E. J. Timm, C. -I. Wu, J. J. D'Angelo, T. P. Hogan, and E. Lara-Curzio, "Room-Temperature Mechanical Properties of LAST (Pb-Sb-Ag-Te) Thermoelectric Materials as a Function of Cooling Rate During Ingot Casting," Philosophical Magazine Letters, 89:267-275 (2009).

[22] J. E. Ni, F. Ren, E. D. Case, and E. J. Timm, "Porosity Dependence of Elastic Moduli in LAST (Lead-Antimony-Silver-Tellurium) Thermoelectric Materials," Materials Chemistry and Physics, 118:459-466 (2009).

[23] F. Ren, E. D. Case, E. J. Timm, E. Lara-Curzio, and R. M. Trejo, "Anomolous TemperatureDependent Young's Modulus of a Cast LAST (Pb-Sb-Ag-Te) Thermoelectric Material," Acta Materialia, 58:31-38 (2010).

[24] A. Q. Morrison, E. D. Case, F. Ren, A. J. Baumann, D. C. Kleinow, J. E. Ni, T. P. Hogan, J. D'Angelo, N. A. Matchanov, T. J. Hendricks, N. K. Karri, C. Cauchy, J. Bernard, and M. G. Kanatzidis, "Elastic Modulus, Biaxial Flexure Strength, Electrical and Thermal Transport Properties of Thermally Fatigued Hot Pressed LAST and LASTT Thermoelectric Materials," Materials Chemistry and Physics, 134:973-987 (2012).

[25] F. Ren, E. D. Case, J. R. Sootsman, M. G. Kanatzidis, H. Kong, C. Uher, E. Lara-Curzio, and R. M. Trejo, "The High-Temperature Elastic Moduli of Polycrystalline PbTe Measured by Resonant Ultrasound Spectroscopy," Acta Materialia, 56:5954-63 (2008).

[26] F. Ren, E. D. Case, E. J. Timm, and H. J. Schock, "Hardness as a Function of Composition for N-Type LAST Thermoelectric Material," Journal of Alloys and Compounds, 455:340-345 (2008).

[27] F. Ren, E. D. Case, J. R. Sootsman, M. G. Kanatzidis, H. Kong, C. Uher, E. Lara-Curzio, and R. M. Trejo, "The High-Temperature Elastic Moduli of Polycrystalline PbTe Measured by Resonant Ultrasound Spectroscopy," Acta Materialia, 56:5954-5963 (2008). 
[28] J. R. Salvador, J. Yang, X. Shi, H. Wang, A. A. Wereszczak, H. Kong, and C. Uher, "Transport and Mechanical Properties of Yb-Filled Skutterudites," Philosophical Magazine, 89:1517-1534 (2009).

[29] J. R. Salvador, R. A. Waldo, C. A. Wong, M. Tessema, D. N. Brown, D. J. Miller, H. Wang, A. A. Wereszczak, and W. Cai, "Thermoelectric and Mechanical Properties of Melt Spun and Spark Plasma Sintered n-Type Yb- and Ba-Filled Skutterudites," in press, Materials Science and Engineering B (2013).

[30] J. R. Salvador, J. Yang, X. Shi, H. Wang, and A. A. Wereszczak, "Transport and Mechanical Property Evaluation of $(\mathrm{AgSbTe})_{1-\mathrm{x}}(\mathrm{GeTe})_{\mathrm{x}}(\mathrm{x}=0.80,0.82,0.85,0.87,0.90), "$ Journal of Solid State Chemistry, 182:2088-2095 (2009).

[31] S. -C. Ur, P. Nash, and R. Schwarz, "Mechanical and Thermoelectric Properties of $\mathrm{Zn}_{4} \mathrm{Sb}_{3}$ and $\mathrm{Zn}_{4} \mathrm{Sb}_{3}+\mathrm{Zn}$ Directly Synthesized Using Elemental Powders," Metals and Materials International, 11:435-441 (2005).

[32] K. Ueno, A. Yamamoto, T. Noguchi, T. Inoue, S. Sodeoka, and H. Obara, "Optimization of HotPress Conditions of $\mathrm{Zn}_{4} \mathrm{Sb}_{3}$ for High Thermoelectric Performance. II. Mechanical Properties," Journal of Alloys and Compounds, 388:118-121 (2005).

[33] M. K. Ferber, M. G. Jenkins, and A. A. Wereszczak, "Fracture Strength," Mechanical Testing Methodology for Ceramic Design and Reliability, Edts. D. C. Cranmer and D. W. Richerson, Marcel Dekker, New York, NY, 1998.

[34] Standard Test Method for Flexural Strength of Advanced Ceramics at Ambient Temperature, ASTM C 1161, ASTM International, West Conshohocken, PA.

[35] Standard Test Method for Flexure Strength (Modulus of Rupture) of Electronic-Grade Ceramics, ASTM F 417 (withdrawn 2001), ASTM International, West Conshohocken, PA.

[36] S. S. Kim and T. Aizawa, "Crystallographic Anisotropy Control of N-Type Bi-Te-Se Thermoelectric Materials via Bulk Mechanical Alloying and Shear Extrusion," Materials Transactions, 45:918-924 (2004).

[37] S. S. Kim, S. Yamamoto, T. Aizawa, "Thermoelectric Properties of Anisotropy-Controlled P-Type Bi-Te-Sb System via Bulk Mechanical Alloying and Shear Extrusion," Journal of Alloys and Compounds, 375:107-113 (2004).

[38] J. Jiang, L. Chen, S. Bai, Q. Yao, and Q. Wang, "Fabrication and Thermoelectronic Performance of Textured N-Type $\mathrm{Bi}_{2}(\mathrm{Te}, \mathrm{Se})_{3}$ by Spark Plasma Sintering," Materials Science and Engineering $B, 117: 334-338$ (2005).

[39] X. A. Fan, J. Y. Yang, W. Zhu, S. Q. Bao, X. K. Duan, C. J. Xiao, Q. Q. Zhang, and Z. Xie, "Effect of Nominal $\mathrm{Sb}_{2} \mathrm{Te}_{3}$ Content on Thermoelectric Properties of P-Type $\left(\mathrm{Bi}_{2} \mathrm{Te}_{3}\right)_{\mathrm{x}}\left(\mathrm{Sb}_{2} \mathrm{Te}_{3}\right)_{1-\mathrm{x}}$ Alloys by MA-HP," Journal of Physics D: Applied Physics, 39:5069-5073 (2006).

[40] A. A. Wereszczak, T. P. Kirkland, O. M. Jadaan, and H. Wang, "Strength of Bismuth Telluride," Ceramic Engineering and Science Proceedings, 9 30:131-142 (2009).

[41] J. R. Salvador, J. Yang, A. A. Wereszczak, H. Wang, and J. Y. Cho, "Temperature Dependent Tensile Fracture Stress of n- and p-Type Filled-Skutterudite Materials," Science of Advanced Materials, 3:1-10 (2011).

[42] K. Ueno, A. Yamamoto, T. Noguchi, T. Inoue, S. Sodeoka, and H. Obara, "Optimization of Hot-Press Conditions of $\mathrm{Zn}_{4} \mathrm{Sb}_{3}$ for High Thermoelectric Performance. III. Effect of Starting Particle Size on Thermoelectric and Mechanical Properties," Journal of Alloys and Compounds, 392:295-299 (2005). 
[43] Standard Test Method for Monotonic Equibiaxial Flexure Strength of Advanced Ceramics at Ambient Temperature, ASTM C 1499, ASTM International, West Conshohocken, PA.

[44] F. Ren, E. D. Case, E. J. Timm, M. D. Jacobs, and H. J. Schock, "Weibull Analysis of the Biaxial Fracture Strength of a Cast p-Type LAST-T Thermoelectric Material," Philosophical Magazine Letters, 86:673-682 (2006).

[45] Standard Test Methods for Determination of Fracture Toughness of Advanced Ceramics at Ambient Temperature, ASTM C 1421, ASTM International, West Conshohocken, PA.

[46] J. Eilertsen, M. A. Subramanian, and J. J. Kruzic, "Fracture Toughness of $\mathrm{Co}_{4} \mathrm{Sb}_{12}$ and $\mathrm{In}_{0.1} \mathrm{Co}_{4} \mathrm{Sb}_{12}$ Thermoelectric Skutterudites Evaluated by Three Methods," Journal of Alloys and Compounds, 552:492-498 (2013).

[47] G. D. Quinn and R. C. Bradt, "On the Vickers Indentation Fracture Toughness Test," Journal of the American Ceramic Society, 90:673-680 (2007).

[48] Standard Test Method for Monotonic Compressive Strength of Advanced Ceramics at Ambient Temperature, ASTM C 1424, ASTM International, West Conshohocken, PA.

[49] D. Qi, X. Tang, H. Li, Y. Yan, and Q. Zhang, "Improved Thermoelectric Performance and Mechanical Properties of Nanostructured Melt-Spun $\beta-\mathrm{Zn}_{4} \mathrm{Sb}_{3}$," Journal of Electronic Materials, 39:1159-1165 (2010).

[50] Standard Test Method for Knoop Indentation Hardness of Advanced Ceramics, ASTM C 1326, ASTM International, West Conshohocken, PA.

[51] Standard Test Method for Vickers Indentation Hardness of Advanced Ceramics, ASTM C 1327, ASTM International, West Conshohocken, PA.

[52] T. J. Lu and N. A. Fleck, "The thermal shock resistance of solids," Acta Materialia, 46:47554768 (1998).

[53] L. T. Zhao, T. J. Lu, and N. A. Fleck, "Crack Channeling and Spalling in a Plate Due to Thermal Shock Loading," Journal of the Mechanics and Physics of Solids, 48:867-897 (2000).

[54] E. D. Case, The Saturation of Thermomechanical Fatigue in Brittle Materials, ThermoMechanical Fatigue and Fracture, ed. M.H. Alibadi (Southampton, UK: WIT Press 2002), pp. 137 $-208$.

[55] C. M. Cheng, "Resistance to Thermal Shock," Journal of the American Rocket Society, 21:147153 (1951).

[56] S. S. Manson, Thermal Stress and Low-Cycle Fatigue, McGraw-Hill Book Company, New York, pp. 276-286, 1966.

[57] N. Noda, "Thermal Stresses in Materials with Temperature-Dependent Properties," Applied Mechanics Reviews, 44:383 - 397 (1991).

[58] W. D. Kingery, H. K. Bowen, and D. R. Uhlmann, Introduction to Ceramics, Second Edition, Wiley, New York, 1976.

[59] E. D. Case, 2012, Thermo-mechanical properties of thermoelectric materials, Chapter 16 (Pages 16-1 to 16-29) in Thermoelectrics and its Energy Harvesting: Modules, Systems and Applications, CRC Press, Taylor and Francis Group, Boca Raton, Florida.

[60] R. O. Ritchie," Mechanisms Of Fatigue-Crack Propagation in Ductile And Brittle Solids," International Journal of Fracture, 100:55 - 83 (1999). 
[61] R. O. Ritchie, "On the Fracture Toughness of Advanced Materials," Advanced Materials, 21:2103 -2110 (2009).

[62] S. Bhowmick, J. J. Melendez-Martinez, B. R. Lawn, "Bulk Silicon is Susceptible to Fatigue," Applied Physics Letters, 91:201902 (2007).

[63] S. Johnsen, J. Q. He, J. Androulakis, V. P. Dravid, I. Todorov, D. Y. Chung, M. G. Kanatzidis, "High Performance Thermoelectrics from Earth-Abundant Materials: Enhanced Figure of Merit in PbS by Second Phase Nanostructures," Journal of the American Chemical Society, 133: 34603470 (2011).

[64] M. G. Kanatzidis, "Nanostructured Thermoelectrics: The New Paradigm?", Chemistry of Materials, 22:648-659 (2010).

[65] C. G. Fu, H. H. Xie, Y. T. Liu, T. J. Zhu, J. Xie, X. B. Zhao, "Thermoelectric properties of FeVSb half-Heusler compounds by levitation melting and spark plasma sintering," Intermetallics, $32: 39-43$ (2013).

[66] J. Sulistyo, T. Hata, H. Kitagawa, P. Bronsveld, M. Fujisawa, K. Hashimoto, Y. Imamura, "Electrical and thermal conductivities of porous $\mathrm{SiC} / \mathrm{SiO}_{2} / \mathrm{C}$ composites with different morphology from carbonized wood," Journal of Materials Science, 45:1107 - 1116 (2010).

[67] A. S. Fawzi, A. D. Sheikh, V. L. Mathe, "Structural, dielectric properties and AC conductivity of $\mathrm{Ni}_{(1-\mathrm{x})} \mathrm{Zn}_{\mathrm{x}} \mathrm{Fe}_{2} \mathrm{O}_{4}$ spinel ferrites," Journal of Alloys and Compounds, 502: 231 - 237 (2010).

[68] T. P. Hoepfner, E. D. Case, "The porosity dependence of the dielectric constant for sintered hydroxyapatite," Journal of Biomedical Materials Research, 60:643 - 650 (2002).

[69] A. Yang, C. A. Wang, R. Guo, Y. Huang, C. W. Nan, "Effects of sintering behavior on microstructure and piezoelectric properties of porous PZT ceramics," Ceramics International, $36: 549-554(2010)$.

[70] S. Geis, J. Fricke, P. Lobmann, "Electrical properties of PZT aerogels," Journal of the European Ceramic Society, 22:1155 - 1161 (2002).

[71] E. M. M. Ewais, S. Barg, G. Grathwohl, A. A. Garamoon, and N. N. Morgan, "Processing of Open Porous Zirconia via Alkane-Phase Emulsified Suspensions for Plasma Applications," International Journal of Applied Ceramic Technology, 8:85 - 93 (2011).

[72] J. Hostasa, W. Pabst, J. Matejicek, "Thermal Conductivity of $\mathrm{Al}_{2} \mathrm{O}_{3}-\mathrm{ZrO}_{2}$ Composite Ceramics," Journal of the American Ceramic Society, 94:4404-4409 (2011).

[73] F. Cernuschi, P. Bison, A. F. Moscatelli, P. Bison, and A. Moscatelli, "Microstructural characterization of porous thermal barrier coatings by laser flash technique," Acta Materialia, $57: 3460-3471$ (2009).

[74] E. Lopez-Lopez, J. P. Erauw, R. Moreno, C. Baudin, and F. Cambier, "Elastic behaviour of zirconium titanate bulk material at room and high temperature," Journal of the European Ceramic Society, 32:4083 - 4089 (2012).

[75] R. D. Schmidt, E. D. Case, G. J. Lehr, and D. T. Morelli, "Room temperature mechanical properties of polycrystalline $\mathrm{YbAl}_{3}$, a promising low temperature thermoelectric material," Intermetallics, 35: 15 - 24 (2013).

[76] F. Ren, E. D. Case, A. Morrison, M. Tafesse, and M. J. Baumann, "Resonant ultrasound spectroscopy measurement of Young's modulus, shear modulus and Poisson's ratio as a function of porosity for alumina and hydroxyapatite," Philosophical Magazine, 89:1163-1182 (2009). 
[77] A. R. Boccaccini, "Comment on the Effective Elastic Moduli of Porous Ceramic Materials," Journal of the American Ceramic Society, 77:2779-2781 (1994).

[78] X. Fan, E. D. Case, F. Ren, Y. Shu and M. J. Baumann, "Part II: Fracture strength and elastic modulus as a function of porosity for hydroxyapatite and other brittle materials," Journal of the Mechanical Behavior of Biomedical Materials, 8:99-110 (2012).

[79] S. C. Nanjangud, R. Brezny, and D. J. Green, "Strength and Young's Modulus Behavior of a Partially Sintered Porous Alumina," Journal of the American Ceramic Society, 78:266-268 (1995).

[80] L. F. Hu and C. A. Wang, 2010. Effect of sintering temperature on compressive strength of porous yttria-stabilized zirconia ceramics," Ceramics International, 36:1697 - 1710 (2010).

[81] L. J. Vandeperre, J. Wang, and W. J. Clegg, "Effects of porosity on the measured fracture energy of brittle materials," Philosophical Magazine, 84:3689-3704 (2004).

[82] T. P. Hoepfner and E. D. Case, "The influence of the microstructure on the hardness of sintered hydroxyapatite," Ceramics International, 29:699 - 706 (2003).

[83] E. Ryshkewitch, "Compression strength of porous sintered alumina and zirconia," Journal of the American Ceramic Society, 36:65-68 (1953).

[84] W. Duckworth, "Discussion of Ryshkewitch paper by Winston Duckworth," Journal of the American Ceramic Society, 36:68 (1953).

[85] R. W. Rice, Porosity of ceramics, Marcel Dekker, Inc. New York, 1998.

[86] K. K. Phani and S. K. Niyogi, "Young's modulus of porous brittle solids," Journal of Materials Science, 22:257-263 (1987).

[87] J. G. Bai, X. H. Yang, Y. G. Shi, S. C. Xu, and J. F. Yang, "Fabrication of directional SiC porous ceramics using $\mathrm{Fe}_{2} \mathrm{O}_{3}$ as pore-forming agent," Materials Letters, 78:192 - 194 (2012).

[88] Z. P. Hou, F. Ye, L. M. Liu, and Q. Liu, "Fabrication of gradient porous beta-SiAlON ceramics via a camphene-based freeze casting process," Materials Science and Engineering A, 558:742746 (2012).

[89] A. A. Wereszczak, H. -T. Lin, T. P. Kirkland, M. J. Andrews, and S. K. Lee, "Strength and Dynamic Fatigue of Silicon Nitride at Intermediate Temperatures," Journal of Materials Science, 37:2669-2684 (2002).

[90] Zhao, DG, Tian, CW, Liu, YT, Zhan, CW, Chen, LD, High temperature sublimation behavior of antimony in $\mathrm{CoSb}_{3}$ thermoelectric material during thermal duration test, Journal of Alloys and Compounds, 509:3166 - 3171 (2011).

[91] O. Kim-Hak, M. Soulier, P.-D. Szkutnik, S. Saunier, J. Simon, and D. Goeuriot, "Microwave sintering and thermoelectric properties of p-type $\left(\mathrm{Bi}_{0.2} \mathrm{Sb}_{0.8}\right)_{2} \mathrm{Te}_{3}$ powder," Powder Technology, 226:231-234 (2012).

[92] R.D. Schmidt, E. D. Case, J.E. Ni, J.S. Sakamoto, R.M. Trejo, E.Lara-Curzio, E.A. Payzant, M.J. Kirkham, R.A. Peascoe-Meisner, "The temperature dependence of thermal expansion for p-type $\mathrm{Ce}_{0.9} \mathrm{Fe}_{3.5} \mathrm{Co}_{0.5} \mathrm{Sb}_{12}$ and n-type $\mathrm{Co}_{0.95} \mathrm{Pd}_{0.05} \mathrm{Te}_{0.05} \mathrm{Sb}_{3}$ skutterudite thermoelectric materials," Philosophical Magazine, 92:1261-1286 (2012).

[93] J. E. Ni, E. D. Case, R. Stewart, C.-I. Wu, T. Hogan, and M. G. Kanatzidis, "Bloating in $\left(\mathrm{Pb}_{0.95} \mathrm{Sn}_{0.05} \mathrm{Te}\right)_{0.92}(\mathrm{PbS})_{0.08}-0.055 \% \mathrm{PbI}_{2}$ specimens as a result of processing conditions," Journal of Electronic Materials, 41:1153- 1158 (2012). 
[94] J. E. Ni, E. D. Case, R. Stewart, C.-I. Wu, T. Hogan, R. Trejo, M. Kirkham, A. Payzant, E. Lara-Curzio, S. N. Girard, and M. G. Kanatzidis, "X-ray diffraction and dilatometer measurements of the temperature-dependent coefficient thermal expansion for $\mathrm{PbTe}-\mathrm{PbS}$ thermoelectric material," accepted, Journal of Materials Science, (2013).

[95] N.G.D. Murray and D.C. Dunand, "Effect of thermal history on the superplastic expansion of argon-filled pores in titanium: Part I kinetics and microstructure," Acta Materialia, 52:2269-2278 (2004).

[96] N. G. D. Murray and D. C. Dunand, "Effect of thermal history on the superplastic expansion of argon-filled pores in titanium: Part II modeling of kinetics," Acta Materialia, 52:2279-2291 (2004).

[97] S. Oppenheimer and D. C. Dunand, "Solid-state foaming of Ti-6Al-4V by creep or superplastic expansion of argon-filled pores," Acta Materialia, 58: 4387-4397 (2010).

[98] S. Oppenheimer and D. C. Dunand, "Porous NiTi by creep expansion of argon-filled pores," Materials Science and Engineering A, 523:70-76 (2009).

[99] G. Haour and J. W. Rutter, "Morphology of Ch-CuCd3 and $\mathrm{Mg}-\mathrm{Mg}_{2} \mathrm{Si}$ eutectics revealed by selective sublimation," Journal of Crystal Growth, 23:304 - 306 (1974).

[100] J. A. Nesbitt, E. J. Opila, and M. V. Nathal, "In Situ Growth of a $\mathrm{Yb}_{2} \mathrm{O}_{3}$ Layer for Sublimation Suppression for $\mathrm{Yb}_{14} \mathrm{MnSb}_{11}$ Thermoelectric Material for Space Power Applications," Journal of Electronic Materials, 41:1267 - 1273 (2012).

[101] F. Ren, J. Y. Howe, L. R. Walker, E. D. Case, and E. Lara-Curzio, "An in situ SEM experiment to study the thermal stability of a LAST (Lead-Antimony-Silver-Tellurium) thermoelectric material," Philosophical Magazine Letters, 91:443-451 (2011).

[102] Z.-H. Ge, B.-P. Zhang, and Z.-X. Yu, "Effect of spark plasma sintering temperature on thermoelectric properties of $\mathrm{Bi}_{2} \mathrm{~S}_{3}$ polycrystal," Materials Research, 26:2711- 2718 (2011)

[103] L. D. Zhao, B. P. Zhang, W. S. Liu, H. L. Zhang, and J. F. Li, "Effects of annealing on electrical properties of n-type $\mathrm{Bi}_{2} \mathrm{Te}_{3}$ fabricated by mechanical alloying and spark plasma sintering," Journal of Alloys and Compounds, 467:91-97 (2009).

[104] J. E. Ni and E. D. Case, "Thermal Fatigue of Cast and Hot Pressed LAST (lead-antimony-silvertellurium) thermoelectrics," Journal of Electronic Materials, 427:1382 - 1388 (2013).

[105] J. R. Groza, S. H. Risbud, and K. Yamazaki, Journal of Materials Research, 7:2643 (1992).

[106] J. R. Groza, M. Garcia, and J. A. Schneider, "Surface effects in field-assisted sintering," Journal of Materials Research, 16, 286292 (2001).

[107] S. H. Risbud, J. R. Groza, and M. J. Kim, Philosophical Magazine, 69:525 (1994).

[108] E. D. Case and C. Glinka, "Characterization of Microcracks in $\mathrm{YCrO}_{3}$ Using Small Angle Neutron Scattering and Elasticity Measurements," Journal of Materials Science, 19:2962-2968 (1984).

[109] D. T. Smith and L. Wei, "Quantifying local microcrack density in ceramics: a comparison of instrumented indentation and thermal wave techniques," Journal of the American Ceramic Society, 78:1301-1304 (1995).

[110] T. Chotard, J. Soro, H. Lemercier, M. Huger, and C. Gault, "High temperature characterisation of cordierite-mullite refractory by ultrasonic means," Journal of the European Ceramic Society, 28:2129-2135 (2008). 
[111] S. G. Yousef, J. Rodel, E. R. Fuller, Jr., A. Zimmermann, and B. S. El-Dasher, "Microcrack evolution in alumina ceramics: experiment and simulation," Journal of the American Ceramic Society, 88:2809-2816 (2005).

[112] X. Fan, E. D. Case, and M. J. Baumann, "The Effect of Indentation-induced Microcracks on the Elastic Modulus of Hydroxyapatite," Journal of Materials Science, 4717:6333-6345 (2012)

[113] S. I. Rokhlin, Y. C. Chu, and M. Hefetz, "Ultrasonic evaluation of microcrack thermal shock damage," Ceramic Engineering and Science Proceedings, No. 7-8: 14:454-462, (1993).

[114] L. A. Diaz, R. Torrecillas, F. Simonin, and G. Fantozzi, "Room temperature mechanical properties of high alumina refractory castables with spinel, periclase and dolomite additions," Journal of the European Ceramic Society, 28:2853 - 2858 (2008).

[115] E. D. Case, "The effect of microcracking upon the Poisson's ratio for brittle materials," Journal of Materials Science, 19:3702-3712 (1984).

[116] H. Sun and D. T. Morelli, "Thermoelectric Properties of $\mathrm{Co}_{1-\mathrm{x}} \mathrm{Rh}_{\mathrm{x}} \mathrm{Si}_{0.98} \mathrm{~B}_{0.02}$ Alloys," Journal of Electronic Materials, 41:1125 - 1129 (2012).

[117] H. Sun, D. T. Morelli, M. J. Kirkham, H. M. Meyer, and E. Lara-Curzio, "The role of boron segregation in enhanced thermoelectric power factor of $\mathrm{CoSi}_{1-\mathrm{x}} \mathrm{B}_{\mathrm{x}}$ alloys," Journal of Applied Physics, Article 123711 (2011).

[118] G. Rogl, Z. Aabdin, E. Schafler, J. Horky, D. Setman, M. Zehetbauer, M. Kriegisch, O. Eibl, A. Grytsiv, E. Bauer, M. Reinecker, W. Schranz, and P. Rogl, "Effect of HPT processing on the structure, thermoelectric and mechanical properties of $\mathrm{Sr}_{0.07} \mathrm{Ba}_{0.07} \mathrm{Yb}_{0.07} \mathrm{Co}_{4} \mathrm{Sb}_{12}$," Journal of Alloys and Compounds, 537:183 - 189 (2012).

[119] T. Ota, I. Yamai, and J. Takahashi, "Electrical conductivity and thermal expansion of $\mathrm{Nb}_{2} \mathrm{O}_{5}$ ceramics," Advanced Ceramic Materials, 1:371- 377 (1986).

[120] Y. F. Chen, D. Q. Li, Q. H. Jiang, and C. B. Zhou, "Micromechanical analysis of anisotropic damage and its influence on effective thermal conductivity in brittle rocks," International Journal of Rock Mechanics and Mining Sciences, 50:102 - 106 (2012).

[121] Y. Z. Wang, J. J. Hua, Z. W. Liu, Y. Zeng, Y. Zhou, and H. Wang, "Melting index characterization and thermal conductivity model of plasma sprayed YSZ coatings," Journal of the European Ceramic Society, 32:3701 - 3707 (2012).

[122] X. J. Jin, "Martensitic transformation in zirconia containing ceramics and its applications," Current Opinion in Solid State \& Materials Science, 9:313 - 318 (2005).

[123] J. A. Kuszyk and R. C. Bradt, "Grain size/microcracking relations for pseudobrookite oxides," Journal of the American Ceramic Society, 56:420-423 (1973).

[124] E. D. Case, J. R. Smyth, and O. Hunter, "Grain size dependence of microcrack initiation in brittle materials," Journal of Materials Science, 15:149-153 (1980).

[125] J. J. Cleveland and R. C. Bradt, "Grain size dependence of spontaneous cracking in ceramics," Journal of the American Ceramic Society, 61:478-481 (1978).

[126] J. F. Nye, Physical Properties of Crystals, their Representation by Tensors and Matrices, Clarendon Press, Oxford, 1985, pp 22 - 23, $131-149$.

[127] Y. Ohya, Y. Takahashi, and Z. Nakagawa, "Thermal expansion of grain boundary cracked aluminum titanate ceramics," Journal of Materials Science, 31:1361 - 1365 (1996).

[128] R. W. Rice and R. C. Pohanka, "Grain size dependence of spontaneous cracking in ceramics," Journal of the American Ceramic Society, 62:559 - 563 (1979). 
[129] E. D. Case, J. R. Smyth, and O. Hunter, "Microcracking in Large Grain $\mathrm{Al}_{2} \mathrm{O}_{3}$," Materals Science and Engineering, 51:175-179 (1981).

[130] T. P. Hogan, A. Downey, J. Short, J. D’Angelo, C-I Wu, E. Quarez, J. Androulakis, F. P. Poudeu, J. Sootsman, D-Y Chung, M. G. Kanatzidis, S. D. Mahanti, E. Timm, H Schock, Fei Ren, J. Johnson, E. D. Case, "Nanostructured Thermoelectric Materials and High Efficiency Power Generation Modules," Journal of Electronic Materials, 367:704-710 (2007).

[131] J. J. D’Angelo, E. J. Timm, F. Ren, B. D. Hall, E. D. Case, H. Schock, M. Kanatzidis, D.-Y. Chun, T. P. Hogan, "Electrical Contact Fabrication and Measurements of Metals and Alloys to Thermoelectric Materials," Materials Research Society Symposia Proceedings, Vol. 1044, pp. 449- 455 (2008).

[132] B. V. Hiremath, "Evaluation of tumbling processes of multilayer ceramic capacitors for surfacemount device applications," IEEE Transactions on Components, Hybrids, and Manufacturing Technology, 16:822-827 (1993).

[133] G. de Width and N. Sweegers, "The effect of erosional wear on the strength and residual stress during shaping of ceramic multilayer capacitors," Wear, 188:142-149 (1995).

[134] D. H. Park, Y. G. Jung, and U. Paik, "Crack suppression behavior with post-process parameters in BaTiO3-based Ni-MLCCs," Ceramics International, 31:655-661 (2007).

[135] T. J. Hendricks, T. P. Hogan, E. D. Case, C. J. Cauchy, N. K. Karri, J. D'Angelo, C.-I. Wu, A. Q. Morrison, and F. Ren, "Advanced Soldier-Based Thermoelectric Power Systems Using Battlefield Heat Sources, in Energy Harvesting--From Fundamentals to Devices," edited by H. Radousky, J. Holbery, L. Lewis, and F. Schmidt (Mater. Res. Soc. Symp. Proc. Volume 1218E, Warrendale, PA), paper 1218-Z07-02 (2010).

[136] N. Laws and J. R. Brockenbrough, "The effect of micro-crack systems on the loss of stiffness of brittle solids," International Journal of Solids and Structures, 23:1247-1268, (1987).

[137] B. Budianski and R. J. O'Connell, Elastic moduli of a cracked solid, International Journal of Solids and Structures, 12:81-97, (1976).

[138] A. Hoening, "Electrical Conductivity of a Cracked Solid," Pure and Applied Geophysics, 117:690-710, (1978/79).

[139] A. Hoening, "Thermal Conductivity of a Cracked Solid," pp. 281-287 in Environment Effects on Composite Materials, ed. G. S. Springer, Technomic Pub. Co., Lancaster, PA, (1984).

[140] R. W. Rice, Mechanical properties of ceramics and composites, Marcel Dekker, Inc., New York, 2000 .

[141] M. H. Zimmerman, D. M. Baskin, K. T. Faber, E. R. Fuller, Jr., A. J. Allen, and D. T. Keane, "Fracture of a textured anisotropic ceramic," Acta Materialia, 49:3231 - 3242 (2001).

[142] M. T. Barako, W. Park, A. M. Marconnet, M. Asheghi, and K. E. Goodson, "Thermal cycling, mechanical degradation, and the effective figure of merit of a thermoelectric module," Journal of Electronic Materials, 42:372 - 381 (2012). 


\section{APPENDIX A. ELASTIC PROPERTIES OF VARIOUS THERMOELECTRIC MATERIALS}

Elastic properties of various thermoelectric materials

\begin{tabular}{|c|c|c|c|c|}
\hline Material & $\begin{array}{c}\text { Elastic Modulus } \\
\text { (GPa) }\end{array}$ & $\begin{array}{c}\text { Poisson's } \\
\text { Ratio }\end{array}$ & $\begin{array}{c}\text { Test } \\
\text { Method }\end{array}$ & Reference \\
\hline $\mathrm{Ca}_{3} \mathrm{Co}_{4} \mathrm{O}_{9}$ & $\begin{array}{l}45-63 \\
\left(25^{\circ} \mathrm{C}\right) \\
\end{array}$ & & IN & [15] \\
\hline $\begin{array}{l}\text { Half-Heusler } \\
\mathrm{NiZrSn}_{1-\mathrm{x}} \mathrm{Sb}_{\mathrm{x}}\end{array}$ & $\begin{array}{c}111 \\
\left(25^{\circ} \mathrm{C}\right)\end{array}$ & & $\mathrm{SN}$ & [16] \\
\hline $\begin{array}{c}\text { Half-Heusler } \\
\text { MgAgAs }\end{array}$ & $\begin{array}{c}119-271 \\
\left(25^{\circ} \mathrm{C}\right)\end{array}$ & & NP & [17] \\
\hline $\begin{array}{c}\text { Half-Heusler } \\
\text { ZrNiSn }\end{array}$ & $\begin{array}{c}220-240 \\
\left(25^{\circ} \mathrm{C}\right)\end{array}$ & & IN & [18] \\
\hline LAST & $\begin{array}{l}25-70 \\
\left(25^{\circ} \mathrm{C}\right)\end{array}$ & & IN & [19] \\
\hline LAST & $\begin{array}{l}45-60 \\
\left(25^{\circ} \mathrm{C}\right)\end{array}$ & & IN & [20] \\
\hline LAST & $\begin{array}{c}55-38 \\
\left(25-400^{\circ} \mathrm{C}\right)\end{array}$ & $\begin{array}{l}0.28-0.22 \\
\left(25-400^{\circ} \mathrm{C}\right)\end{array}$ & RUS & [20] \\
\hline LAST & $\begin{array}{l}49-53 \\
\left(25^{\circ} \mathrm{C}\right)\end{array}$ & $\begin{array}{c}0.24-0.25 \\
\left(25^{\circ} \mathrm{C}\right)\end{array}$ & RUS & [21] \\
\hline LAST & $\begin{array}{c}58 \\
\left(25^{\circ} \mathrm{C}\right) \\
\text { Lowest Porosity }\end{array}$ & $\begin{array}{c}0.27 \\
\left(25^{\circ} \mathrm{C}\right) \\
\text { Lowest Porosity }\end{array}$ & RUS & [22] \\
\hline LAST & $\begin{array}{c}50-37 \\
\left(25-550^{\circ} \mathrm{C}\right)\end{array}$ & $\begin{array}{l}0.22-0.27 \\
\left(25-550^{\circ} \mathrm{C}\right)\end{array}$ & RUS & [23] \\
\hline LAST & $\begin{array}{c}46.4-56.5 \\
\left(25^{\circ} \mathrm{C}\right)\end{array}$ & $\begin{array}{c}0.26-0.27 \\
\left(25^{\circ} \mathrm{C}\right)\end{array}$ & RUS & [24] \\
\hline $\mathrm{PbTe}$ & $\begin{array}{c}58-45 \\
\left(25-500^{\circ} \mathrm{C}\right) \\
\end{array}$ & $\begin{array}{c}0.3-0.25 \\
\left(25-500^{\circ} \mathrm{C}\right) \\
\end{array}$ & RUS & [25] \\
\hline $\begin{array}{l}\text { Skutterudite } \\
\text { N-type }\end{array}$ & $\begin{array}{c}140-120 \\
\left(25-400^{\circ} \mathrm{C}\right)\end{array}$ & $\begin{array}{c}0.29-0.21 \\
\left(25-400^{\circ} \mathrm{C}\right)\end{array}$ & IE & [1] \\
\hline $\begin{array}{l}\text { Skutterudite } \\
\text { P-type }\end{array}$ & $\begin{array}{c}140-120 \\
\left(25-400^{\circ} \mathrm{C}\right)\end{array}$ & $\begin{array}{c}0.29-0.21 \\
\left(25-400^{\circ} \mathrm{C}\right)\end{array}$ & IE & [1] \\
\hline Skutterudite & $\begin{array}{c}135-130 \\
\left(25-500^{\circ} \mathrm{C}\right)\end{array}$ & $\begin{array}{l}0.20-0.22 \\
\left(25-500^{\circ} \mathrm{C}\right)\end{array}$ & RUS & [28] \\
\hline $\begin{array}{c}\text { Skutterudite } \\
\text { N-type }\end{array}$ & $\begin{array}{c}135 \\
\left(25^{\circ} \mathrm{C}\right)\end{array}$ & $\begin{array}{c}0.20 \\
\left(25^{\circ} \mathrm{C}\right)\end{array}$ & RUS & [29] \\
\hline $\begin{array}{c}\text { Skutterudite } \\
\text { P-type }\end{array}$ & $\begin{array}{c}139 \\
\left(25^{\circ} \mathrm{C}\right)\end{array}$ & $\begin{array}{c}0.20 \\
\left(25^{\circ} \mathrm{C}\right)\end{array}$ & RUS & [29] \\
\hline TAGS & $\begin{array}{c}50 \\
\left(25^{\circ} \mathrm{C}\right) \\
\end{array}$ & $\begin{array}{c}0.24 \\
\left(25^{\circ} \mathrm{C}\right) \\
\end{array}$ & RUS & [30] \\
\hline $\mathrm{Zn}_{4} \mathrm{Sb}_{3}$ & $\begin{array}{c}72 \\
\left(25^{\circ} \mathrm{C}\right)\end{array}$ & $\begin{array}{c}0.26 \\
\left(25^{\circ} \mathrm{C}\right)\end{array}$ & RUS & [31] \\
\hline $\mathrm{Zn}_{4} \mathrm{Sb}_{3}$ & $\begin{array}{l}58-76 \\
\left(25^{\circ} \mathrm{C}\right)\end{array}$ & & IE & [32] \\
\hline
\end{tabular}

RUS $=$ resonant ultrasound spectroscopy. $\mathrm{IE}=$ impulse excitation. $\mathrm{SN}=$ sonic. $\mathrm{IN}=$ indentation. $\mathrm{NP}=$ not provided. 



\section{APPENDIX B. UNAXIAL FLEXURE STRENGTH OF VARIOUS THERMOELECTRIC MATERIALS}

Unaxial flexure strength of various thermoelectric materials

\begin{tabular}{|c|c|c|c|c|}
\hline Material & $\begin{array}{l}\text { Strength* } \\
\text { (MPa) }\end{array}$ & Scatter** & $\begin{array}{c}\text { Test } \\
\text { Conditions }\end{array}$ & Reference \\
\hline $\begin{array}{l}\text { Bi-Te-Sb } \\
\text { N-type }\end{array}$ & $166(\mathrm{AS})$ & NP & $\begin{array}{l}3 \text { - pt - bend, } \\
\text { no other info } \\
\text { provided }\end{array}$ & [36] \\
\hline $\begin{array}{l}\text { Bi-Te-Sb } \\
\text { P-type }\end{array}$ & $\begin{array}{c}70-120(\mathrm{AV}) \\
\left(25^{\circ} \mathrm{C}\right)\end{array}$ & NP & $\begin{array}{l}3-\mathrm{pt}-\text { bend, } \\
\text { no other info } \\
\text { provided }\end{array}$ & [37] \\
\hline $\mathrm{Bi}_{2}(\mathrm{Te}, \mathrm{Se})_{3}$ & $\begin{array}{c}67-82(\mathrm{AV}) \\
\left(25^{\circ} \mathrm{C}\right)\end{array}$ & $\begin{array}{l}5(\mathrm{AV}) \\
\left(25^{\circ} \mathrm{C}\right)\end{array}$ & $\begin{array}{l}3 \text { - pt - bend, } \\
\text { ASTM F417 }\end{array}$ & [38] \\
\hline$\left(\mathrm{Bi}_{2} \mathrm{Te}_{3}\right)_{\mathrm{x}}\left(\mathrm{Sb}_{2} \mathrm{Te}_{3}\right)_{1-\mathrm{x}}$ & $\begin{array}{c}60(\mathrm{AV}) \\
\left(25^{\circ} \mathrm{C}\right)\end{array}$ & NP & $\begin{array}{l}3 \text { - pt - bend, } \\
\text { no other info } \\
\text { provided }\end{array}$ & [39] \\
\hline $\begin{array}{l}\text { Bismuth } \\
\text { telluride } \\
\text { N-type }\end{array}$ & $\begin{array}{l}80-70(\mathrm{CS}) \\
\left(25-225^{\circ} \mathrm{C}\right)\end{array}$ & $\begin{array}{c}11-10(\mathrm{WM}) \\
\left(25-225^{\circ} \mathrm{C}\right)\end{array}$ & $\begin{array}{c}2 \times 2 \times 15 \mathrm{~mm}, \\
\text { bar length parallel to } \\
\text { pressing axis, } \\
3-\mathrm{pt} \text { - bend, \& } \\
12.7 \mathrm{~mm} \text { span }\end{array}$ & [40] \\
\hline $\begin{array}{l}\text { Bismuth } \\
\text { telluride } \\
\text { N-type }\end{array}$ & $\begin{array}{l}50-40(\mathrm{CS}) \\
\left(25-225^{\circ} \mathrm{C}\right)\end{array}$ & $\begin{array}{c}9-5(\mathrm{WM}) \\
\left(25-225^{\circ} \mathrm{C}\right)\end{array}$ & $\begin{array}{c}2 \times 2 \times 15 \mathrm{~mm}, \\
\text { bar length } \\
\text { perpendicular to } \\
\text { pressing axis, } \\
3 \text { - pt - bend, } \& \\
12.7 \mathrm{~mm} \text { span }\end{array}$ & [40] \\
\hline $\begin{array}{l}\text { Bismuth } \\
\text { telluride } \\
\text { P-type }\end{array}$ & $\begin{array}{l}80-60(\mathrm{CS}) \\
\left(25-225^{\circ} \mathrm{C}\right)\end{array}$ & $\begin{array}{c}16-11(\mathrm{WM}) \\
\left(25-225^{\circ} \mathrm{C}\right)\end{array}$ & $\begin{array}{c}2 \times 2 \times 15 \mathrm{~mm}, \\
\text { bar length parallel to } \\
\text { pressing axis, } \\
3-\mathrm{pt}-\text { bend, \& } \\
12.7 \mathrm{~mm} \text { span }\end{array}$ & [40] \\
\hline $\begin{array}{l}\text { Bismuth } \\
\text { telluride } \\
\text { P-type }\end{array}$ & $\begin{array}{l}40-35(\mathrm{CS}) \\
\left(25-225^{\circ} \mathrm{C}\right)\end{array}$ & $\begin{array}{c}7(\mathrm{WM}) \\
\left(25-225^{\circ} \mathrm{C}\right)\end{array}$ & $\begin{array}{l}2 \times 2 \times 15 \mathrm{~mm}, \\
\text { bar length } \\
\text { perpendicular to } \\
\text { pressing axis, } \\
3-\mathrm{pt} \text { - bend, \& } \\
12.7 \mathrm{~mm} \text { span } \\
\end{array}$ & [40] \\
\hline $\mathrm{Ca}_{3} \mathrm{Co}_{4} \mathrm{O}_{9}$ & $\begin{array}{l}25-325 \\
\left(25^{\circ} \mathrm{C}\right)\end{array}$ & NP & $\begin{array}{l}3 \text { - pt -bend } \\
\text { unconventional } \\
\text { "welded" } \\
\text { multilaminate }\end{array}$ & [15] \\
\hline $\begin{array}{l}\text { Half-Heusler } \\
\text { MgAgAs }\end{array}$ & $\begin{array}{c}107-260(\mathrm{AV}) \\
\left(25^{\circ} \mathrm{C}\right)\end{array}$ & NP & 3 - pt - bend & {$[17]$} \\
\hline $\begin{array}{l}\text { PbTe } \\
\text { N-Type }\end{array}$ & $\begin{array}{l}72(\mathrm{CS}) \\
\left(25^{\circ} \mathrm{C}\right)\end{array}$ & $\begin{array}{c}6(\mathrm{WM}) \\
\left(25^{\circ} \mathrm{C}\right)\end{array}$ & $\begin{array}{l}2 \times 2 \times 11 \mathrm{~mm}, \\
3-\mathrm{pt}-\text { bend, \& } \\
6.35 \mathrm{~mm} \mathrm{span}\end{array}$ & [28] \\
\hline
\end{tabular}




\begin{tabular}{|c|c|c|c|c|}
\hline Material & $\begin{array}{l}\text { Strength* } \\
\text { (MPa) }\end{array}$ & Scatter** & $\begin{array}{c}\text { Test } \\
\text { Conditions }\end{array}$ & Reference \\
\hline $\begin{array}{c}\text { Skutterudite } \\
\text { N-type }\end{array}$ & $\begin{array}{l}91(\mathrm{CS}) \\
86(\mathrm{AS}) \\
\left(25^{\circ} \mathrm{C}\right)\end{array}$ & $\begin{array}{c}7.3(\mathrm{WM}) \\
13 \mathrm{MPa}(\mathrm{SD}) \\
\left(25^{\circ} \mathrm{C}\right)\end{array}$ & $\begin{array}{l}2 \times 1.5 \times 28 \mathrm{~mm}, \\
4-\mathrm{pt}-\text { bend, } \& \\
10 / 20 \mathrm{~mm} \text { spans }\end{array}$ & [1] \\
\hline $\begin{array}{c}\text { Skutterudite } \\
\text { P-type }\end{array}$ & $\begin{array}{l}40(\mathrm{CS}) \\
37(\mathrm{AS}) \\
\left(25^{\circ} \mathrm{C}\right)\end{array}$ & $\begin{array}{c}5.6(\mathrm{WM}) \\
7 \mathrm{MPa}(\mathrm{SD}) \\
\left(25^{\circ} \mathrm{C}\right)\end{array}$ & $\begin{array}{l}2 \times 1.5 \times 28 \mathrm{~mm}, \\
4-\mathrm{pt}-\text { bend, } \& \\
10 / 20 \mathrm{~mm} \text { spans }\end{array}$ & [1] \\
\hline $\begin{array}{l}\text { Skutterudite } \\
\text { N-type }\end{array}$ & $\begin{array}{c}105-130(\mathrm{CS}) \\
93-120(\mathrm{AS}) \\
\left(25-500^{\circ} \mathrm{C}\right) \\
\end{array}$ & $\begin{array}{c}2.4-7.3(\mathrm{WM}) \\
21-39 \mathrm{MPa}(\mathrm{SD}) \\
\left(25-500^{\circ} \mathrm{C}\right)\end{array}$ & $\begin{array}{c}1.5 \times 1.5 \times 12 \mathrm{~mm} \\
3 \text { - pt - bend, \& } \\
8.0 \mathrm{~mm} \text { span }\end{array}$ & [12] \\
\hline Skutterudite & $\begin{array}{c}125(\mathrm{CS}) \\
\left(25^{\circ} \mathrm{C}\right)\end{array}$ & $\begin{array}{c}4(\mathrm{WM}) \\
\left(25^{\circ} \mathrm{C}\right)\end{array}$ & $\begin{array}{l}2 \times 2 \times 11 \mathrm{~mm}, \\
3-\mathrm{pt}-\text { bend, \& } \\
6.35 \mathrm{~mm} \text { span }\end{array}$ & [28] \\
\hline $\begin{array}{l}\text { Skutterudite } \\
\text { P-type }\end{array}$ & $\begin{array}{c}90-113(\mathrm{CS}) \\
82-104(\mathrm{AS}) \\
\left(25-500^{\circ} \mathrm{C}\right) \\
\end{array}$ & $\begin{array}{c}3.4-9.7(\mathrm{WM}) \\
11-24 \mathrm{MPa}(\mathrm{SD}) \\
\left(25-500^{\circ} \mathrm{C}\right)\end{array}$ & $\begin{array}{c}1.5 \times 1.5 \times 12 \mathrm{~mm} \\
3 \text { - pt - bend, } \& \\
8.0 \mathrm{~mm} \mathrm{span}\end{array}$ & [12] \\
\hline $\begin{array}{l}\text { Skutterudite } \\
\text { N-type }\end{array}$ & $\begin{array}{c}160-143(\mathrm{CS}) \\
154-135(\mathrm{AS}) \\
\left(25-500^{\circ} \mathrm{C}\right) \\
\end{array}$ & $\begin{array}{c}8.8-11(\mathrm{WM}) \\
16-25 \mathrm{MPa}(\mathrm{SD}) \\
\left(25-500^{\circ} \mathrm{C}\right) \\
\end{array}$ & $\begin{array}{c}1.7 \times 1.7 \times 12 \mathrm{~mm} \\
3 \text { - pt - bend, \& } \\
8.0 \mathrm{~mm} \text { span }\end{array}$ & [41] \\
\hline $\begin{array}{l}\text { Skutterudite } \\
\text { P-type }\end{array}$ & $\begin{array}{c}135-147(\mathrm{CS}) \\
132-142(\mathrm{AS}) \\
\left(25-500^{\circ} \mathrm{C}\right)\end{array}$ & $\begin{array}{c}11-28(\mathrm{CS}) \\
7-21 \mathrm{MPa}(\mathrm{SD}) \\
\left(25-500^{\circ} \mathrm{C}\right)\end{array}$ & $\begin{array}{c}1.7 \times 1.7 \times 12 \mathrm{~mm} \\
3 \text { - pt - bend, \& } \\
8.0 \mathrm{~mm} \mathrm{span}\end{array}$ & [41] \\
\hline $\mathrm{Zn}_{4} \mathrm{Sb}_{3}$ & $\begin{array}{c}70(\mathrm{AS}) \\
\left(25^{\circ} \mathrm{C}\right)\end{array}$ & NP & $\begin{array}{c}\text { specimen size not } \\
\text { provided, } \\
3-\mathrm{pt} \text { - bend, } \\
16 \mathrm{~mm} \mathrm{span}\end{array}$ & [32] \\
\hline $\mathrm{Zn}_{4} \mathrm{Sb}_{3}$ & $\begin{array}{c}60-80(\mathrm{AS}) \\
\left(25^{\circ} \mathrm{C}\right)\end{array}$ & NP & $\begin{array}{l}\text { specimen size not } \\
\text { provided, } \\
3-\mathrm{pt}-\text { bend, } \\
16 \mathrm{~mm} \text { span }\end{array}$ & [42] \\
\hline
\end{tabular}

* $\quad \mathrm{CS}=$ characteristic for Weibull distribution, $\mathrm{AS}=$ average for Normal distribution, $\mathrm{AV}=$ ambiguous value.

** $\mathrm{WM}=$ Weibull modulus for Weibull distribution, $\mathrm{SD}=$ standard deviation for Normal distribution, NR $=$ Not provided. 


\section{APPENDIX C. BIAXIAL FLEXURE STRENGTH OF VARIOUS THERMOELECTRIC MATERIALS}

Biaxial flexure strength of various thermoelectric materials

\begin{tabular}{|c|c|c|c|c|}
\hline Material & $\begin{array}{c}\text { Strength* } \\
\text { (MPa) }\end{array}$ & Scatter** & $\begin{array}{c}\text { Test } \\
\text { Conditions }\end{array}$ & Reference \\
\hline $\begin{array}{l}\text { Bismuth } \\
\text { telluride } \\
\text { P-type }\end{array}$ & $\begin{array}{c}45(\mathrm{CS}) \\
\left(25^{\circ} \mathrm{C}\right)\end{array}$ & $\begin{array}{c}15(\mathrm{WM}) \\
\left(25^{\circ} \mathrm{C}\right)\end{array}$ & $\begin{array}{c}1 \times 15 \times 15 \mathrm{~mm}, \\
\text { square parallel to } \\
\text { pressing axis, } \\
\text { ring-on ring, \& } \\
6.35 / 12.7 \mathrm{~mm} \text { spans }\end{array}$ & [40] \\
\hline $\begin{array}{l}\text { Bismuth } \\
\text { telluride } \\
\text { P-type }\end{array}$ & $\begin{array}{c}30(\mathrm{CS}) \\
\left(25^{\circ} \mathrm{C}\right)\end{array}$ & $\begin{array}{c}16(\mathrm{WM}) \\
\left(25^{\circ} \mathrm{C}\right)\end{array}$ & $\begin{array}{l}1 \times 15 \times 15 \mathrm{~mm}, \\
\text { square perpendicular } \\
\text { to pressing axis, } \\
\text { ring-on ring, \& } \\
6.35 / 12.7 \mathrm{~mm} \text { spans } \\
\end{array}$ & [40] \\
\hline LAST & $\begin{array}{c}15.3(\mathrm{CS}) \\
\left(25^{\circ} \mathrm{C}\right)\end{array}$ & $\begin{array}{c}3.2(\mathrm{WM}) \\
\left(25^{\circ} \mathrm{C}\right)\end{array}$ & $\begin{array}{c}22 \mathrm{~mm} \text { dia. } \times 3 \mathrm{~mm} \\
\text { thick, } \\
\text { ball-on-ring, } \\
15.8 \mathrm{~mm} \text { dia support } \\
\text { ring }\end{array}$ & [44] \\
\hline LAST & $\begin{array}{c}13-26(\mathrm{AS}) \\
\left(25^{\circ} \mathrm{C}\right)\end{array}$ & $\begin{array}{c}2.4-6.3(\mathrm{SD}) \\
\left(25^{\circ} \mathrm{C}\right)\end{array}$ & $\begin{array}{c}22 \mathrm{~mm} \text { dia. } \times 3 \mathrm{~mm} \\
\text { thick, } \\
\text { ball-on-ring, } \\
15.8 \mathrm{~mm} \text { dia support } \\
\text { ring } \\
\end{array}$ & [20] \\
\hline LAST & $\begin{array}{c}29(\mathrm{AS}) \\
\left(25^{\circ} \mathrm{C}\right)\end{array}$ & $\begin{array}{l}12(\mathrm{SD}) \\
\left(25^{\circ} \mathrm{C}\right)\end{array}$ & $\begin{array}{l}25 \mathrm{~mm} \text { dia. } \times 2.5 \mathrm{~mm} \\
\text { thick, } \\
\text { ring-on-ring, } \\
\text { sizes of rings not } \\
\text { provided }\end{array}$ & [24] \\
\hline
\end{tabular}

* $\quad \mathrm{CS}=$ characteristic for Weibull distribtuion, $\mathrm{AS}=$ average for Normal distribution.

** $\mathrm{WM}=$ Weibull modulus for Weibull distribution, $\mathrm{SD}=$ standard deviation for Normal distribution. 
